OPEN ACCESS

Edited by:

Adrian Preda,

University of California, Irvine, USA

Reviewed by:

Anthony John Hannan,

University of Melbourne, Australia

Omar Cauli,

University of Valencia, Spain

Francis Bambico,

University of Toronto, Canada

*Correspondence:

Silvana Gaetani

silvana.gaetani@uniroma1.it

Specialty section:

This article was submitted to

Neuropharmacology,

a section of the journal

Frontiers in Neuroscience

Received: 29 May 2015

Accepted: 14 December 2015

Published: 12 January 2016

Citation:

Romano A, Tempesta B, Micioni Di Bonaventura MV and Gaetani S (2016) From Autism to Eating

Disorders and More: The Role of

Oxytocin in Neuropsychiatric

Disorders. Front. Neurosci. 9:497.

doi: 10.3389/fnins.2015.00497

\section{From Autism to Eating Disorders and More: The Role of Oxytocin in Neuropsychiatric Disorders}

\author{
Adele Romano ${ }^{1}$, Bianca Tempesta ${ }^{1}$, Maria Vittoria Micioni Di Bonaventura ${ }^{2}$ and \\ Silvana Gaetani ${ }^{1 *}$ \\ 1 Department of Physiology and Pharmacology "Vittorio Erspamer", Sapienza University of Rome, Rome, Italy, \\ ${ }^{2}$ Pharmacology Unit, School of Pharmacy, University of Camerino, Camerino, Italy
}

Oxytocin (oxy) is a pituitary neuropeptide hormone synthesized from the paraventricular and supraoptic nuclei within the hypothalamus. Like other neuropeptides, oxy can modulate a wide range of neurotransmitter and neuromodulator activities. Additionally, through the neurohypophysis, oxy is secreted into the systemic circulation to act as a hormone, thereby influencing several body functions. Oxy plays a pivotal role in parturition, milk let-down and maternal behavior and has been demonstrated to be important in the formation of pair bonding between mother and infants as well as in mating pairs. Furthermore, oxy has been proven to play a key role in the regulation of several behaviors associated with neuropsychiatric disorders, including social interactions, social memory response to social stimuli, decision-making in the context of social interactions, feeding behavior, emotional reactivity, etc. An increasing body of evidence suggests that deregulations of the oxytocinergic system might be involved in the pathophysiology of certain neuropsychiatric disorders such as autism, eating disorders, schizophrenia, mood, and anxiety disorders. The potential use of oxy in these mental health disorders is attracting growing interest since numerous beneficial properties are ascribed to this neuropeptide. The present manuscript will review the existing findings on the role played by oxy in a variety of distinct physiological and behavioral functions (Figure 1) and on its role and impact in different psychiatric disorders. The aim of this review is to highlight the need of further investigations on this target that might contribute to the development of novel more efficacious therapies.

Keywords: oxytocinergic system, autism, eating disorders, anxiety, mood disorders

\section{INTRODUCTION}

\section{History and Structure of Oxytocin}

The neuropeptide oxytocin (oxy), was discovered in 1906 by Henry Dale, who observed that extracts from human posterior pituitary gland were able to induce uterus contractions in a pregnant cat; the name oxy, derives from the Greek words " $\omega \kappa \nu \xi$ окох $\xi$," meaning "swift birth."

In 1984, Ivell and Richter elucidated the structure of the oxy gene (Ivell and Richter, 1984), and in 1992 the sequence of the oxy receptor (oxyr) was reported (Kimura et al., 1992). Oxy is a nonapeptides with a disulfide bridge between Cys residues 1 and 6 that creates a six-amino acid cyclic structure and a $\mathrm{COOH}$-terminal $\alpha$-amidated three-residue tail. 


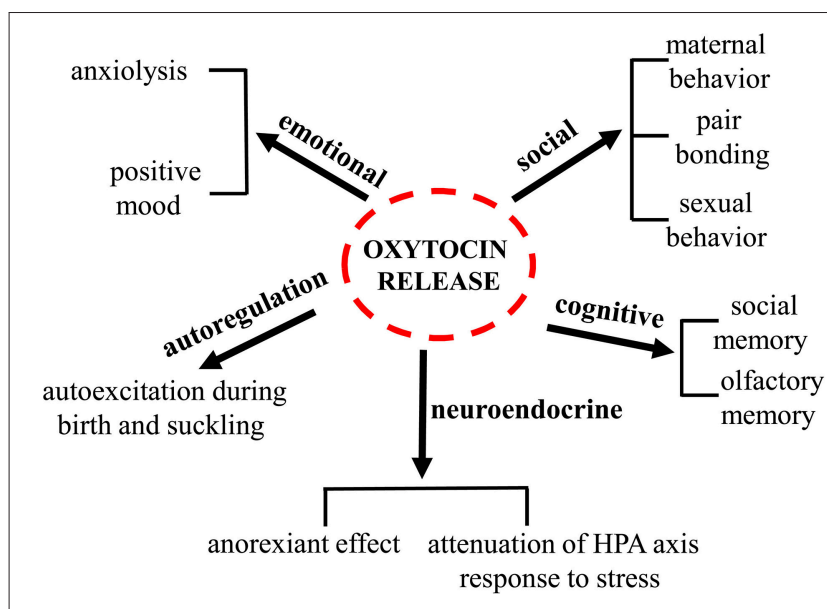

FIGURE 1 | Oxytocin regulatory control of different and complex processes.

\section{Synthesis and Localization}

Oxy is synthesized as a preprohormone precursor protein that includes the oxy carrier protein neurophysin I (Brownstein et al., 1980). Although neurophysin is apparently devoid of any biologically activity, different observations suggests that it might exert a protective role against oxy enzymatic damage and it has been extensively studied for its involvement in the regulation of oxy neurosecretory pathways (Legros and Geenen, 1996; de Bree, 2000). The inactive preprohormone protein is hydrolyzed by a variety of enzymes in small fragments and the last reaction that generates oxy is catalyzed by a peptidylglycine alpha-amidating monooxygenase (Brownstein et al., 1980; Burbach et al., 2001; von Eggelkraut-Gottanka and Beck-Sickinger, 2004). The oxy gene, located on chromosome two in mice, three in rats, and 20 in humans (Dutil et al., 2001), is composed of three exons, each of them encoding for a particular portion of the peptide (Gimpl and Fahrenholz, 2001).

\section{The Oxytocinergic System Hypothalamus-Hypophysis}

The hypothalamic-neurohypophysial system represents the major oxy neurosecretory system and consists of the paraventricular (PVN) and supraoptic (SON) nuclei (Swanson and Kuypers, 1980; Rhodes et al., 1981) and their axons reaching the neurohypophysis. However, the neurons of PVN and SON project extensively also to other brain areas such as the arcuate nucleus (Arc), the median eminence (ME), the lateral septum (LS) and the medial amygdala nucleus (MeA; Pittman et al., 1981). Within the PVN, two populations of oxy neurons have been identified: "magnocellular" and "parvocellular" neurons. Oxy is mainly synthesized in the magnocellular portions of the PVN and SON (Swaab et al., 1975). Oxytocinergic magnocellular neurons terminate in the posterior lobe of the pituitary gland and also innervate the Arc, the LS, the MeA, and the ME (Pittman et al., 1981). Once activated, magnocellular oxytocinergic neurons, release oxy from the nerve terminals to the posterior pituitary; from here oxy is secreted into the bloodstream, so that it can produce its effect on organs expressing oxyrs located in the rest of the body (Gimpl and Fahrenholz, 2001). The release of oxy from the neurohypophysis into the blood stream is not accompanied by an increase of the peptide at the central level, thus indicating that oxy does not readily cross the blood brain barrier (BBB). In accordance with this observation, peripheral stimulation of oxytocinergic system such as during milk suckling or vaginal dilatation may not change oxy levels in the central nervous system (CSF; Gimpl and Fahrenholz, 2001). Moreover, while stimulation of the PVN evokes oxy release at both central and pheripheral level, electrical stimulation of the rat neurohypophysis only evokes oxy release into the blood (Harris et al., 1981); moreover oxy circulating levels are reduced after hypophysectomy in rats while its concentration increases in the CSF (Dogterom et al., 1977). The oxy half-life is $28 \mathrm{~min}$ in the CSF, compared to 1-2 min into the blood; in the CSF, oxy is normally present at concentrations of $10-50 \mathrm{pM}$, slightly higher than those in plasma (Jones and Robinson, 1982; Meyer et al., 1987). Moreover, oxy release has been shown to occur not only at the axonal levels but also locally from dendrites in both the PVN and SON (Neumann et al., 1996).

Furthermore, oxy can act as an intrinsic self neuromodulator; oxy release within the SON is pivotal for the coordinated depolarization of oxy neurons during lactation and for the positive feedback mechanism mediated by oxyrs on its own release during parturition (Neumann et al., 1996).

The parvocellular neurons, that are smaller than magnocellular neurons, are located in the dorsal-caudal portion of the PVN and terminate principally to the nucleus of solitary tract (NST), the dorsal motor nucleus of the vagus (DMNV), the rostral ventrolateral medulla, and the sympathetic centers in the spinal cord (Amico et al., 1990; Rinaman, 1998; Tóth et al., 1999).

Finally, it has been proposed that oxy may participate in the physiological regulation of the adenohypophysial hormones prolactin adrenocorticotropic hormone (Page et al., 1990), and gonadotropins (Robinson and Evans, 1990). This hypothesis is supported by evidence demonstrating that hypothalamic oxytocinergic fibers reach also the anterior part of the pituitary gland via the hypophyseal portal system (Amar and Weiss, 2003).

\section{Oxytocin Receptor}

The oxy receptor (oxyr) is a 389 aminoacid polypeptide belonging to the G-protein coupled receptor family with seven transmembrane domains. Specifically this receptor is coupled to a Gq/11 $\alpha$ protein that stimulates the activity of phospholipase C. This leads to the generation of second messengers, release of $\mathrm{Ca}^{2+}$ from the intracellular storages, and activation of protein kinase type $\mathrm{C}$. These two conditions can trigger several cellular events such as the contraction of smooth cells, cellular excitation, and modification of gene expressions (Gimpl and Fahrenholz, 2001).

The oxyr has been identified not only in the brain but also in several peripheral organs. In the rat CNS, oxyrs are present in several regions, including the olfactory system, cortex, thalamus, basal ganglia, ventromedial region of the hypothalamus, bed nucleus of the stria terminalis, central amygdala, ventral 
subiculum, hippocampus, nucleus accumbens, brain stem, and spinal cord (Gimpl and Fahrenholz, 2001). Interestingly, their expression density changes according to the age (Gimpl and Fahrenholz, 2001).

In human brain oxyrs are not present in the olfactory bulbs, entorhinal cortex nor in the amygdala or hippocampus but they are mainly expressed in the pars compacta of substantia nigra and globus pallidus, as well as in the anterior cingulate and medial insula (Gimpl and Fahrenholz, 2001). In peripheral organs oxyrs are expressed in the uterus, mammary gland, ovary, kidney, heart, bone, and endothelial cells (Gimpl and Fahrenholz, 2001). Through the activation of oxyrs in the bone tissue oxy was shown to be implicated in bone growth and in the remodeling of bone structures (Breuil et al., 2011).

\section{Neuromodulatory Control Exerted by Oxytocin}

Similarly to other neuropeptides, oxy is able to influence neurotransmission within the nervous system in a manner that is different from other classical neurotransmitters such as GABA, serotonin and dopamine (reviewed by Ludwig and Leng, 2006). The first main difference between the action of neuropeptidergic and classical neurotransmitters is linked to their very different turnover: neuropeptides show a much longer half-life (about $20 \mathrm{~min}$ ) than neurotransmitters (about $5 \mathrm{~ms}$ ), due to their much slower degradation (Mens et al., 1983). As a consequence, neuropeptides can produce their effects in the CNS at longer distances and in broader regions of diffusion (Landgraf and Neumann, 2004; Ludwig and Leng, 2006).

The second main difference concerns the modality of their release, being neuropeptides stored in core-dense vesicles that are released not only at the axonal endings but also at the somatodendritic levels and are much larger than synaptic vesicles that store and release classical neurotransmitters at the synaptic terminals (Morris and Pow, 1991). Both these two aspects make the neuromodulatory actions of neuropeptides much broader and less spatial/temporal specific with respect to classical neurotransmitters. However, at the same time, neuropeptidergic neurons form also synaptic connections with other neurons and, therefore, neuropeptides are able to play also a more specific action at their axon terminal that is more similar to the function of other classical neurotransmitters. The oxytocinergic system shares these common aspects with many other neuropeptides.

How oxy can actually affect neurotransmission in different brains areas and the effects that this modulation can produce on behaviors and neuronal function has started to be elucidated recently.

Oxy is able to rapidly change brain state to modulate synaptic plasticity in specific areas. These includes the mouse auditory cortex, which has been recently demonstrated (Marlin et al., 2015), or the hippocampus (Mühlethaler et al., 1984; Zaninetti and Raggenbass, 2000; Owen et al., 2013), or the nucleus accumbens (Dölen et al., 2013). In particular it has been emerging that in these areas oxy neuromodulation acts sharpening neuronal responses to increase the salience of specific stimuli. This action is the result of a dual action: at the signal generation that is increased and at the background noise that is dampened. For example, Marlin and colleagues have studied the role of oxy in the mouse maternal behavior of pup retrieval and demonstrated that oxy is able to regulate the neuronal responses induced by pup calls in the auditory cortex of the mothers. This action is not symmetrical in both hemispheres and leads to a lateralization of the response with a greater stimulation of the left auditory cortex, where a higher density of oxyr is observed mostly on inhibitory interneurons expressing parvalbumin and somatostatin. The activation of these receptors by oxy released from projections of PVN neurons seems to be required mainly to trigger, rather than to maintain, the retrieval behavior and it is able to produce a specific equilibrium of the degree and timing of inhibitory signal with excitatory signal, which produces and increase of the salience of pup calls.

A similar mechanism was demonstrated also in the hippocampus. At this level oxyr are mostly expressed in the soma and dendrites of GABAergic interneurons, whose firing is increased by their activation. Interneuron firing, in turn, suppresses the activity of pyramidal neurons (Mühlethaler et al., 1984; Zaninetti and Raggenbass, 2000). Owen et al. (2013) showed how this positive effect of oxy on the firing of fastspiking interneurons is able to enhance the signaling to cortical structures while concurrently lowering the background noise. In fact, the increased firing of fast-spiking interneurons is able to suppress the spontaneous firing of pyramidal hippocampal neurons. At the same time, a use-dependent depression develops at the synapse between the fast-spiking interneuron and the pyramidal cell that leads to the enhancement of spike throughput. This circuitry, which can be activated by any manipulation able to stimulate fast-spiking interneurons, leads to a significant enhancement of the fidelity and timing of spike transmission through the network.

In the nucleus accumbens oxy was demonstrated to act causing a presynaptic long term depression (LTD) of excitatory inputs that plays a key role in the positive reinforcing properties of social interaction in rodents (Dölen et al., 2013). In particular, Dölen and collaborators demonstrated the expression of oxyr on the axon terminals of serotonergic neurons arising from the dorsal raphe nucleus. The activation of oxyr at these terminals is able to induce a presynaptic form of LTD in medium spiny neurons through the involvement of the subtype $5 \mathrm{HT} 1 \mathrm{~B}$ of serotonergic receptors and such mechanism plays a necessary role for social reward in mice. Recent findings from the Piomelli's laboratory demonstrated that this mechanism of synaptic plasticity triggered by oxy in the nucleus accumbens involves also another important neural component of the circuitry: the endocannabinoid system. In fact, the activation of oxyr is able to trigger the synthesis and release of anandamide in the nucleus accumbens that, in turn, activates local CB1 receptors (Wei et al., 2015). The involvement of these receptors appears necessary in mediating the rewarding properties of social interaction. This observation suggests the hypothesis that CB1 activation in the nucleus accumbens might participate in the oxy-triggered synaptic plasticity that mediates oxy effects in this behavioral context, as the activation of $\mathrm{CB} 1$ receptors has been demonstrated to induce presynaptic LTD in other brain stuctures (Robbe et al., 2002; Gerdeman and Lovinger, 2003). 
These mechanisms of oxy action in different brain structures provide insight into how a diffusely distributed neuromodulatory signal can specifically influence the performance of complex networks in a manner that ensure synapse specificity and millisecond definition.

\section{Physiological Role of Oxytocin Oxytocin in the Lactation and Parturition}

The oxytocinergic system plays a crucial role in the induction of labor, due to its uterotonic action exerted on the endometrium smooth muscle. Therefore, selective oxy receptor antagonist may be useful for the prevention of premature delivery and dysmenorrhea (Williams et al., 1998; Blanks and Thornton, 2003; Leng et al., 2005).

During parturition, the mechanical stimulation of the uterus provokes, via the vagal and pelvic nerves, the activation of the NST via A2 adrenergic cells (Russell et al., 2003) and the ventromedial medulla, which, in turn, projects to magnocellular neurons. During lactation, oxy induces milk ejection, acting on myoepithelial cells of the mammillary glands (Blanks and Thornton, 2003). A reflex response to the stimulation of the nipple by suckling is able to activate oxy secretion not only from the axons reaching the neurohypophysis, but also from the soma and dendrites of oxy neurons in the SON, where oxy acts in a paracrine manner to trigger and maintain a synchronized bursting (Richard et al., 1997; Ludwig, 1998). This mechanism occurs in concert with other important factors that contribute to milk ejection, such as the sight, smell, and sound of the newborn (Leng et al., 2005).

\section{Oxytocin and Social Behavior}

Oxy seems to be implicated in several and complex social behaviors in a range of mammals (Carter, 1992; Bosch and Neumann, 2012). One of the most studied aspects is the regulation of maternal behavior (Bosch and Neumann, 2012). In particular, oxy promotes maternal care in lactating rats and plays a key role in bond formation between mother and offspring (reviewed by Ross and Young, 2009). When central oxy production is blocked or after the central administration of an oxyr antagonist the maternal bond formation is impaired (Ross and Young, 2009). In addition, oxy is also critical for the formation of the bond from the infant to his mother, as suggested by the experimental observation that mouse pups lacking oxy gene fail to prefer their biological mother over a foster ones (Ross and Young, 2009).

Oxy is also involved in the mechanisms regulating the development of adult-adult pair; in fact, oxy plays a role in the partner preference of monogamous prairie voles. In particular, in female prairie voles central administration of oxy induces pairbonding without prior mating (Williams et al., 1994) and this behavior is blocked by the treatment with oxyr antagonist given before mating (Insel and Hulihan, 1995). The identification of conspecifics is a crucial requirement for the formation of pair bonds (Insel and Fernald, 2004); oxy takes part to the processes that regulate social memory, in terms of social learning and social recognition (Benelli et al., 1995; Engelmann et al., 1998) and the pretreatment with an oxyr antagonist prevents this ability (Benelli et al., 1995; Engelmann et al., 1998; Lukas et al., 2013).

Interestingly, the administration of a low dose of oxy, within the amygdala, re-establish normal social behavior in oxy null mice (Ferguson et al., 2002). The observation that this effect occurs when oxy administration precedes the first exposure to a conspecific during the test of social recognition suggests that the oxytocinergic system in mice is crucial for the memory processes associated with the acquisition of the social information rather than the consolidation (Ferguson et al., 2002). In accordance with such hypothesis, the central administration of an oxyr antagonist in the medial part of the amygdala results in impairment of recognition of conspecifics encountered previously (Ferguson et al., 2002). The effects of oxy on social behavior are complex and may be dependent on the context in which they occur. In fact, oxy seems to promote sociality when social cues in the environment are interpreted as "safe" and oxy may induce defensive behavior when the social cues are interpreted as "unsafe" (Bartz et al., 2011; Olff et al., 2013). This latter effect is also present when oxy is administered to subjects with an adverse early history (Bhandari et al., 2014).

Finally, it is well known that "mind reading" is an essential basis of human social interaction and the role that oxy plays in the formation of social bonds is also related to its role of promoting the understanding of the mental state of individuals from the interpretation of their facial cues (Domes et al., 2007).

\section{Oxytocin and Stress}

Oxy release from the pituitary gland occurs also in response to different stressful stimuli, such as conditioned fear, pain, electric footshock, exposure to novel environments, restraint stress, etc. The stimulation of oxy release under these circumstances is mediated, at least in part, by noradrenergic neurons containing prolactin-releasing peptide in the NST (Onaka, 2004). Also in humans acute psychologically stressful stimuli have been shown to increase plasma oxy concentrations (Sanders et al., 1990; Pierrehumbert et al., 2010).

A large body of evidence indicates that oxy displays potent anxiolytic properties and dampens the neuroendocrine response of the hypothalamic-pituitary-adrenal (HPA) axis to stress (Viero et al., 2010). Intriguingly Dabrowska and collaborators (Dabrowska et al., 2011) have shown the presence of a potential reciprocal interaction between the hypothalamic oxytocinergic system and the corticotrophin-releasing factor (CRF) system. The authors demonstrated that CRF neurons of both PVN and bed nucleus of stria terminalis would be highly responsive to local oxy release, leading to the onset of an inhibitory circuit, which could reduce the HPA axis activation in response to stress.

\section{Oxytocin and Sexual Behavior}

Oxy has been strongly linked to the stimulation of sexual behavior and it is released in response to sexual interactions in rats (Carter, 1992). Also in humans, both man and women, oxy plasma levels are increased during orgasm 
and sexual arousal (Carmichael et al., 1987; Carter, 1992). In male rats oxy facilitates copulation, when injected into the medial preoptic area and this effect is abolished by the pre-administration of an oxyr antagonist (Gil et al., 2011). Moreover, oxy injection in the ventral tegmental area (VTA) induces penile erection by interacting with the dopaminergic system (Melis et al., 2007; Baskerville et al., 2009). Interestingly, intranasal oxy administration evokes in women a marked increase of sexual desire, which is associated with vaginal transudate (Anderson-Hunt and Dennerstein 1994, 1995).

Finally, oxy levels fluctuate throughout the menstrual cycle in fertile women not using oral contraceptives; in particular during the luteal phase oxy plasma levels are lower compared to those observed in the ovulatory phase (Altemus et al., 2001; Salonia et al., 2005). Moreover, during the ovulation, the endogenous oxy activity is suppressed (Evans et al., 2003).

\section{Oxytocin and Cardiovascular Control}

Both magnocellular and parvocellular PVN neurons are involved in the autonomic control of the heart and vessels and a role of central oxy with respect to cardiovascular control has been established (Coote, 2005) demonstrating also the expression of oxyrs in cardiomyocytes and in the wall of large blood vessels (Gutkowska et al., 1997; Jankowski et al., 1998, 2000); the content of oxyrs in the heart is lower than in the uterus, but the size of the receptor is similar (Gutkowska et al., 1997; Cicutti et al., 1999). The rat heart is a site of oxy synthesis and release; in particular oxy was detected in all four chambers with the highest concentration in the right atrium. The heart oxy is structurally identical, to the oxy found in the hypothalamus (Jankowski et al., 1998).

The oxytocinergic system in rat heart is physiologically relevant for a number of reasons:

1) oxy is a cardiomiogenic factor. In fact oxy induces the differentiation of the so called "side population" (SP) progenitor cells into beating cardiomyocytes (Oyama et al., 2007); moreover oxy treatment of the progenitor cells expressing the stem cell antigen-1 (Sca-1) induces the gene expression of cardiac transcription factors, contractile proteins, and stimulates spontaneous beating (Matsuura et al., 2004).

2) oxy exerts a cardioprotective action by stimulating the heart release of the atrial natriuretic peptide (ANP; Favaretto et al., 1997; Gutkowska et al., 1997) a well established cardioprotective agent (Kasama et al., 2008).

3) oxy produces a negative cronotropic effect which is protective on ischemia-reperfusion-induced myocardial damage. In particular, Ondrejcakova and his collaborators showed that perfusion with oxy before ischemia resulted in a reduction of the infarct size (Ondrejcakova et al., 2009). Both central and peripheral administration of oxy induce a long-term decrease of blood pressure in rats (Petersson et al., 1996) and cause a concentration-dependent reduction in both heart rate and force of contraction of isolated atria (Favaretto et al., 1997).
Interestingly, changes in brain oxy content were found in spontaneously hypertensive rats (SHRSP). In particular, oxy content was markedly reduced in the hypothalamus, the brain stem and spinal cord of SHRSP, compared to age-matched normotensive rats (Gaida et al., 1985) and SHRSP rats were found to express lower levels of oxy mRNA in the SON and PVN (van Tol et al., 1988).

\section{Oxytocin and Analgesia}

The analgesic properties of oxy seem to derive mostly from its interaction with the central endogenous opioid system ( $\mathrm{Gu}$ and Yu, 2007; Han and Yu, 2009).

From the hypothalamus, oxy is transported not only to the pituitary gland but also to other brain areas involved in the nociceptive signaling such as the amygdala (Gimpl and Fahrenholz, 2001; Crock et al., 2012) and to the spinal cord in the dorsal horn (Zimmerman et al., 1984), where it modulates pain perception (Yang et al., 2007a) Several behavioral studies in rodents demonstrated that intrathecal administered oxy may exert antinociceptive effects in a dose-dependent manner (Lundeberg et al., 1993; Xu and Wiesenfeld-Hallin, 1994; Yang et al., 2007a). Similarly, oxy was found to induce a dosedependent increase in the hindpaw withdrawal latency to noxious thermal and mechanical stimulation in rats, when injected into the nucleus accumbens or in the central amygdala, whereas the administration of the oxyr antagonist atosiban in this latter area was able to block oxy antinociceptive effect ( $\mathrm{Gu}$ and $\mathrm{Yu}$, 2007; Han and $Y u, 2009$ ). Intraperitoneal administration of oxy was able to decrease the licking/biting response of the formalin injected pow in a model of tonic continous pain in mice and such effects was shown to involve opioid receptors (both $\kappa$ and $\delta$ ) and voltage-gated calcium channels (Reeta et al., 2006). Moreover, endogenous oxy was shown to attenuate the vocalization induced by electrical whisker pad stimulation in decerebrated newborns by inducing a reduction of the depolarizing action of GABA on nociceptive neurons; an effects that was blocked by the administration of an oxyr antagonist (Mazzuca et al., 2011).

A variety of non noxious stimuli stimulate the oxytocinergic system; thermal stimulation $\left(40^{\circ} \mathrm{C}\right)$, vibration $(100 \mathrm{~Hz})$, and electro-acupuncture $(2 \mathrm{~Hz})$ induce a significant increase of oxy levels in plasma and/or in CSF of rats (Uvnäs-Moberg et al., 1993). On this regard Yang and his collaborators demonstrated that central oxy administration enhances acupuncture analgesia, while central administration of anti-oxy serum weakened acupuncture analgesia in a dose-dependent manner (Yang et al., 2007b). Oxy was also shown to exhibit antinociceptive effects in neuropathic animals where it reduced post-discharge produced by electrical stimulation (Condés-Lara et al., 2005). A fewer set of data is available in support of the analgesic role of oxy in humans. One study indicated that low oxy levels are significantly associated with ratings of greater pain, stress, and depression in patients affected by fibromyalgia (Anderberg and UvnäsMoberg, 2000). In another clinical study intrathecal oxy acute administration was able to relieve from low back pain (Yang, 1976), through a mechanism likely involving the endogenous opiate system, as suggested by the effects of naloxone preadministration in the prevention of such effect. 


\section{OXYTOCIN AND NEUROPSYCHIATRIC DISORDERS}

\section{Oxytocin and Autism}

Autism spectrum disorders (ASD) refer to a group of complex and prevalent developmental impairments characterized by deficits in social interaction, verbal skills, repetitive behavior, and reduced range of interests and activities (Muhle et al., 2004). As already described in previous paragraphs, oxy is implicated in social recognition, attachment, and stereotyped behaviors (Insel et al., 1999; Ferguson et al., 2000; Takayanagi et al., 2005); moreover oxy has a recognized role in anxiety (Labuschagne et al., 2010; Amico et al., 2014), which is often a comorbid feature of autism (South et al., 2011; Vannucchi et al., 2014).

Deficits in oxy signaling mechanism have been proposed to contribute to the onset of several behavioral abnormalities of ASD (Insel et al., 1999; Insel and Young, 2001). Given the potential link between oxy functions and core deficits in ASD, oxy has received increasing attention in the last years as a potential therapeutic target for these disorders.

Human studies have demonstrated that oxy promotes retention of social information and reduced repetitive behaviors (Hollander et al., 2003, 2007) in individuals with ASD. Moreover, studies performed on children and adolescents with ASD subjected to intranasal oxy administration over a period of 2-6month suggest that oxy improves social communication in these individuals (Kosaka et al., 2012; Tachibana et al., 2013).

A direct involvement of oxy in autism has been suggested already in 1998 by Modahl et al. (1998), who reported decreased plasma oxy levels in autistic children, as compared with agematched healthy controls. In this study, a decrease in oxy levels correlated to a low development of social and communication skills.

Interestingly, it has been shown that individuals with autism display a defect in processing of the peptide oxy; in these subjects the decreased plasma oxy levels were associated with an increase of oxy-extended peptide inactive form (Green et al., 2001). This inactive peptide form, which is normally detected during the fetal life, is present in high quantity in the blood of autistic children (Green et al., 2001), thus possibly interfering with the functioning of the oxytocinergic system.

However, oxy levels did not correlate with impairments in social interaction, communication, or stereotyped behavior in adult subjects suffering of ASD, as measured by the Autism Diagnostic Interview-Revised (ADI-R) (Lord et al., 1994). On the same line, Jansen et al. (2006) found that ASD adults showed increased basal oxy plasma levels. Based on these observations, it seems that the oxytocinergic system might become dysfunctional during different developmental stages (adults vs. children) over the lifespan of individuals with ASD, but further studies are necessary to confirm these findings.

Several large-scale studies have demonstrated the association between genetic vulnerability on the gene encoding oxyr and ASD. Specific gene polymorphisms for oxyr gene were associated to autism in the Han Chinese population (Wu et al., 2005). On the same line, Jacob et al. (2007) revealed a similar finding in autistic Caucasian children and adolescents. These findings were extended by Lerer et al. (2008), who demonstrated not only a significant association between SNPs and ASD but they also reported an association between oxyr variants, intelligence quotient and scores of the Vineland Adaptive Behavioral Scales (VABS), an effective assessment tool to evaluate the social abilities of an individual. Moreover, Yrigollen et al. (2008) found a significant association of both the oxy gene (two SNPs) and oxyr (three SNPs) and autism diagnosis as well as Campbell et al. (2011) and his collaborators reported an association of oxyr genetic polymorphisms with social communication dysfunction in ASD subjects.

Conversely, Tansey et al. (2010) failed to demonstrate an association between 18 single nucleotide polymorphisms (SNPs) in oxyr gene and ASD, although, the authors did not evaluate the SNP mostly involved (rs2254298) in the studies performed before.

Interestingly, oxyr gene expression may be affected by epigenetic modifications, as suggested by the observation of a significant association between methylation of oxyr and decreased oxyr mRNA levels in the temporal cortex tissue collected post mortem from individuals affected by autism (Gregory et al., 2009).

The evidences reported above suggest that there is still lack of consistency among different studies and probably this is due to the heterogeneous nature of ASD and to the enormous quantity of genes to consider.

A large number of studies have investigated the impact of exogenous oxy administration in individuals with ASD. Oxy intravenous administration reduced repetitive behaviors in adults with ASD compared to placebo (Hollander et al., 2003). In a second experiment (Hollander et al., 2007), adult subjects diagnosed with autism were treated with intravenous oxy and were subjected to a task in which they had to identify the mood of the person who held the speech which pronounced four sentences of four emotional intonations (happy, indifferent, angry, sad). All subjects treated with oxy improved the comprehension of affective speech from pre- to post-infusion and the authors interpreted this result as oxy increasing retention of social cognition.

Intranasal oxy administration has been demonstrated to improve the performance of both adolescent (Guastella et al., 2010) and adult (Domes et al., 2007) males with ASD on the socalled "Reading the Mind in the Eyes Task" (RMET) that provides the identification of emotions on the basis on the observation of the eyes of a face. Moreover, intranasal oxy administration increased total gaze time spent on face regions by increased fixation time on the eye region displayed by adults with ASD (Andari et al., 2010). Finally, long-term daily intranasal oxy administration improved social behaviors in both male and females with ASD (Anagnostou et al., 2012; Kosaka et al., 2012).

In accordance with this large set of clinical data, subcronically administered oxy was able to improve the social deficits and the repetitive behavior that can be observed in two inbred mouse strains (Teng et al., 2013), which exhibit some of the behavioral abnormalities of subjects suffering from ASD, such as the BALB/cByJ mice (Moy et al., 2007) and the C58/J mice (Ryan et al., 2009). Another preclinical evidence in support of the role of oxy in ASD derives from studies conducted on mice 
lacking the gene that codifies for the cell-adhesion molecule contactin-associated protein-like 2 (Cntnap2), which in humans is associated to a syndrome characterized by cortical dysplasia, focal epilepsy and, in most cases, ASD. These mice have a decreased number of oxy neurons in the PVN and a general reduction of oxy levels and show deficits of social behavior that an acute intraperitoneal treatment with oxy is able to restore (Peñagarikano et al., 2015).

The distribution of oxyrs in specific brain areas involved in social behavior, overlap with $\mu$-opioid receptors and this observation suggest the existence of an interaction between the two systems that might play a role in ASD. Gigliucci and collaborators, contributed to the understanding of the role of oxy in ASD by testing oxy effects in mice lacking $\mu$-opioid receptors, which are considered an experimental model of autism since they display abnormal social interaction, increased self-grooming, stereotyped behavior, and a general a of sociability (Gigliucci et al., 2014). These mice display an increase in oxyrs expression in the nucleus accumbens, medial and central amygdala, and in the medial anterior olfactory nucleus; intranasal oxy administration to these mice was able to rescue the social impairments observed in different behavioral tests (Gigliucci et al., 2014).

Importantly, it is known that there is a window of time in post-natal life of the rodent, during which there is a peak in the concentration of oxyr in the neocortex (Hammock and Levitt, 2013) and administration of oxy in this age can be responsible of several behaviors that the individual can develop later in adulthood. On this line it has been reported that when oxy is administered daily in the first postnatal week can prevent deficits in social behavior and learning abilities in mice deficient for the melanoma antigen family L2 (Magel2), a gene which has been found mutated in patients with autism (Meziane et al., 2014).

Recent advances in understanding possible neural systems implicated in the etiopatogenesis of autism have highlighted that some forms of autism might be caused by an imbalance between excitation and inhibition at various neuronal systems. It has been reported that both autistic human subjects and animal models of autism display dysfunction in GABA signaling (Rubenstein and Merzenich, 2003; Gogolla et al., 2009; Blatt and Fatemi, 2011). Interestingly, GABA which in adults has an inhibitory role, during early development plays an excitatory action (BenAri et al., 2007). The shift from excitatory to inhibitory, occurs at birth, and has been shown that oxy plays a key role in this process, causing a reduction in the intracellular concentration of $\mathrm{Cl}^{-}$(Tyzio et al., 2006) and this effect disappears in CA3 hippocampal neurons of two mouse model of autism: mouse in utero exposed to valproate and mice carrying the fragile $\mathrm{x}$ mutation (Tyzio et al., 2014). In the same study, the authors also reported that prenatal treatment with the oxy receptor antagonist SSR126768A in naïve animals induces alterations similar to those observed in both mouse models of autism (Tyzio et al., 2014).

In summary, all these evidences point toward oxy potential as an agent to improve social cognition, functioning and repetitive behavior in ASD, although the literature still very tentative due to methodological constraints.

\section{Oxytocin and Eating Disorders}

Several lines of evidence have established a link between oxy signaling and food intake and in the last years this peptide has gained attention for its effects in the treatment of obesity (Kublaoui et al., 2008; Maejima et al., 2009, 2011; Deblon et al., 2011; Zhang and Cai, 2011; Zhang et al., 2011; Morton et al., 2012). Clinical investigations list oxy in a high number of studies on caloric intake, gastric emptying, and obesity (Blevins and Ho, 2013).

Meal-related stimuli such as the intake of food (Johnstone et al., 2006), the release of the satiety signal cholecystokinin (Olson et al., 1992;), gastric distension (Renaud et al., 1987; Nelson et al., 1998), or stimulation of gastric vagal afferents (Ueta et al., 2000; Tang et al., 2006) are associated with activation of oxy neurons within the PVN and SON, release of oxy into the bloodstream, and activation of hindbrain areas that regulate meal size.

Oxy- and oxyr knock out mice develop late-onset obesity (Takayanagi et al., 2008; Camerino, 2009) and both systemic (Arletti et al., 1989, 1990) and central oxy administration decrease food intake; moreover the pre-treatment with an oxy receptor antagonist blocks this effect (Arletti et al., 1989, 1990; Olson et al., 1991). Oxy treatment has been evaluated in several animal models of obesity. In particular, central oxy chronic treatment induces a dose-dependent decrease in body weight gain, stimulates lipolysis and fatty acid $\beta$-oxidation, reduces glucose intolerance, and insulin resistance in diet-induced obese (DIO) rats (Deblon et al., 2011; Morton et al., 2012). Similarly, subcutaneous daily oxy administration reduces food intake, body weight, ameliorates fatty liver, and glucose intolerance in DIO mice (Maejima et al., 2011). In accordance with this observation, a very recent study demonstrated that a 4-week chronic oxy treatment reduces body weight in DIO rhesus monkeys by decreasing food intake and increasing energy expenditure and lipolysis (Blevins et al., 2015).

Oxy antiobesity treatment has proved valid also in animal models that exhibit an altered leptin signaling, in fact oxy induces anorexia in leptin-resistant Zucker-fatty rats (Maejima et al., 2009), causes a dose-dependently reduction in food intake and body weight gain in ob/ob animals (Altirriba et al., 2014) and suppresses food intake by activating vagal afferent neurons in leptin-resistant $\mathrm{db} / \mathrm{db}$ mice (Iwasaki et al., 2015). Specifically, oxy decreases food intake by reducing meal size and increasing the latency to the first meal, while oxy antagonists stimulate food intake by increasing meal size (Arletti et al., 1990). Moreover, oxyr null mice show an increase in meal size during the dark cycle (Takayanagi et al., 2008). Interestingly, it has been shown that oxy injections into the dorsal vagal complex inhibits gastric motility in rats (Rogers and Hermann, 1987) and this is in line with the findings that oxy excites neurons of both NST and DMNV, which respond to gastric distension (McCann and Rogers, 1990).

Consistently with the presence of oxyrs along the gastrointestinal tract (Qin et al., 2009), it has been shown that systemic oxy reduces gastric empting in laboratory rats and this effect is blocked by the pre-treatment with an oxyr antagonist (Wu et al., 2003, 2008). Moreover, it has been suggested that the anorexiant effect of oxy might involve in part 
the inhibition of reward circuits: in fact, Carson and collaborators demonstrated that systemic oxy reduces methamphetamineinduced activity in reward related brain areas. Furthermore, the same group demonstrated that systemic oxy reduces the motivation to consume methamphetamine and reduces the methamphetamine induced hyperactivity in mice (Carson et al., 2010a,b). These results support the potential use of oxy as a beneficial treatment for addictive disorders. Interestingly, in a recent research (Ott et al., 2013) Ott and collaborators examined the food intake and reward-driven snack intake in humans subjected to intranasal oxy administration. The authors found that oxy markedly reduced the intake of chocolate cookies, further supporting a pivotal contribution of oxytocinergic system in the regulation of reward-related eating behavior. In addition to inhibit food intake, both central and pheripheral oxy administrations reduce body weight by increasing energy expenditure (Morton et al., 2012) and lipolysis (Muchmore et al., 1981). In contrast, oxy antagonist increases body weight gain (Zhang and Cai, 2011) and mice genetically lacking oxy or oxyr develop obesity during adulthood (Camerino, 2009). In accordance with these observations, mice modified genetically to have a reduced PVN oxy signaling, such as single-minded 1 gene (SIM1) haploinsufficient mice (Xi et al., 2012) or synaptotagmin 4 (SYT4) null mice (Zhang et al., 2011), are characterized by a reduction in energy expenditure, hyperphagia and obesity. The excessive body weight in SIM1 haploinsufficient mice can be restored by oxy treatment (Kublaoui et al., 2008). Likewise, humans with mutations of SIM1 show severe eating disorders (Holder et al., 2000; Swarbrick et al., 2011). Whether oxy treatment would be able to control body weight gain in this subject remained unexplored.

Although research on the implication of the oxytocinergic system in anorexia nervosa (AN) are at the beginning and all those existing are based on small sample sizes, it has been suggested that the complex array of neuroendocrine disturbances in AN involves the oxytocinergic system. Demitrack et al. (1990) reported that women affected by restricting anorexia show oxy CSF levels significantly lower than the levels observed in control subjects. Moreover, women affected by AN display a decreased overnight secretion of oxy compared to healthy controls and this is associated with a decrease in bone mineral density and body fat (Lawson et al., 2011). Furthermore, both bulimic and anorectic patients present lower serum activity of the prolyl-endopeptidase, an enzyme implicated in the cleavage of several active neuropeptides, such as oxy (Maes et al., 2001). Finally, results from two pilot studies revealed changes on eating-related indices, following intranasal administration of oxy in AN subjects, compared to placebo. In particular in one study, the researchers observed a reduction in eating disorder and in the other study they found that oxy significantly reduced selective attention toward anxiety laden eating stimuli (Maguire et al., 2013).

\section{Prader-Willi Syndrome}

The Prader Willi syndrome (PWS) is a genetic disorder characterized by hypotonia, developmental disability, hypogonadism and, importantly, gross body weight gain and insatiable hunger due to impaired perception of satiety.

In animal research, it has been shown that mice lacking one of the members of the melanoma antigen gene (MAGE) family, called MAGED1 display an increase in daily food intake accompanied by a reduction in mature hypothalamic oxy levels; moreover they develop adult-onset obesity and reduced activity (Dombret et al., 2012). MAGED1 together with MAGEL2 and Necdin are genes critically involved in PWS (reviewed by Francis et al., 2014). It has been shown that MAGEL2 play a crucial role in suckling, thus MAGEL2-deficient mice had a high mortality in the neonatal life, which is due to their suckling defects. Interestingly, these mutant mice display a reduction in oxy hypothalamic levels and a single injection of oxy soon after birth, rescued the phenotype of Magel2 mutant pups, allowing them to survive (Schaller et al., 2010).

Finally Necdin mutant mice showed a reduced number of oxy producing neurons (Muscatelli et al., 2000) and presented respiratory problems that evoke those observed in PWS patients (Wharton and Bresnan, 1989).

In PWS subjected, intranasal oxy administration increased trust in others and decrease sadness and disruptive behavior (Tauber et al., 2011). In addition, results from a postmortem study of PWS subjects, reported a $42 \%$ reduction of oxyexpressing neurons in the PVN and a smaller oxy cells volumes, as compared to healthy controls (Swaab et al., 1995). Moreover, PWS subjects present increased oxy CSF levels similarly to obsessive compulsive disorders (OCD) patients (reviewed by Marazziti and Catena Dell'osso, 2008). Interestingly, the prevalence of OCD in PWS is high (Dykens et al., 1996), suggesting that this two pathologies might share common abnormalities at the level of the oxytocinergic system.

\section{Oxytocin and Other Psychiatric Disorders}

Given to its effect on cognition, memory, and social functioning, oxy has been studied in the pathophysiology of a wide range of psychiatric disorders including schizophrenia, mood, anxiety, and obsessive compulsive-disorders. In the present paragraph we report both preclinical and clinical findings obtained in studies that evaluated the activity of the oxytocinergic system in these disorders.

Both preclinical and clinical literature suggests that oxy has a role in schizophrenia. In mice, for example, it has been demonstrated that the oxytocinergic system is affected and that oxy may explicate its potential antipsychotic effect through the inhibition of the mesolimbic dopaminergic circuit (Macdonald and Feifel, 2012). Moreover, a positive correlation between plasma/CSF oxy levels and schizophrenia has been reported. In particular, it has been found an increase of CSF oxy levels in adult males with paranoid schizophrenia and increased plasma oxy level in schizophrenic patients particularly in those taking neuroleptics (Beckmann et al., 1985).

Interestingly, in a very recent study, it has been reported that the higher plasma oxy levels in schizophrenic patients might be due to a compensatory response to a lower sensitivity of the oxyr to circulating levels of the hormone (Strauss et al., 2015). Similar findings were obtained also from the measure 
of the levels of human neurophysin II (hNPII). Interestingly CSF levels (Linkowski et al., 1984) and serum level (Legros et al., 1992) of hNPII were increased in individuals with schizophrenia compared to healthy volunteers. In contrast to the evidences reported above, no differences in oxy concentrations in the CSF (Glovinsky et al., 1994; Sasayama et al., 2012) or plasma (Goldman et al., 2008) were found between patients with schizophrenia and healthy controls. We think that inconsistencies in oxy levels among studies may reflect differences in evaluating peripheral vs. cerebrospinal fluid levels, sample-related differences, sex, age, race, and differences in disease chronicity.

Interestingly, genetic studies revealed that two different oxyr SNPs were associated with schizophrenia (Montag et al., 2013) and Souza et al. (2010) evaluated the association between both oxy and oxyr variants with symptom severity and the response to clozapine in individuals with schizophrenia, since it has been demonstrated that clozapine enhances oxy release in rats (Kiss et al., 2010). Teltsh et al. (2012) found an association between one variant in the $5^{\prime}$-as well as $3^{\prime}$ promoter region of oxy and schizophrenia in a large clan of ArabIsraeli individuals. The first study conducted on men with the "simple form of schizophrenia" and subjected to intravenous or intranasal oxy administration revealed an improvement of depression and negative symptoms (Bakharev et al., 1986). When oxy was administred intranasally to healthy, polydipsic, and nonpolydipsic patients with schizophrenia, who were asked to rate the presence and intensity of various facial emotions, Goldman et al. (2011) demonstrated that emotion recognition was improved in polydipsic patients but not in non polydipsic patients. Moreover, it has been demonstrated that oxy improves cognition in schizophrenia, as suggested by the findings obtained by Feifel et al. (2012) demonstrating the ability oxy treatment to improve verbal memory learning tasks.

In the last years it has been evaluated the effect of the chronic exposure to a combination of intranasal oxy and atypical antipsychotic in schizophrenic patients; the results obtained demonstrated that oxy improved negative symptoms when administered twice per day in a range between 3 and 6 weeks (Feifel et al., 2010; Modabbernia et al., 2013; Gibson et al., 2014). On the other hand, the group of Davis et al. (2014) did not report any improvement of negative symptoms after a single dose of intranasal oxy given twice a week before a session of social skills training. It is worth to emphasize that these clinical trials, which suggest the possible beneficial role of intranasal administration of oxy, are in contrast with preclinical studies performed on laboratory rodents. In fact a number of recent findings suggest that the chronic treatment with oxy not only produce no benefit, but may further worsen social interaction in rodents (Bales et al., 2013; Rault et al., 2013; Huang et al., 2014). Finally in a very recent study (Shin et al., 2015), in which the authors evaluated the effect of a single dose of intranasal oxy on brain activity in patients with schizophrenia, oxy was able to modulate the neuronal response to different facial emotions. Although more and larger studies are necessary to determine the impact and the generalizability of the findings described above, overall, oxy shows great promise as being a possible and effective treatment for patients with schizophrenia.

As far as mood disorders, a large body of studies have examined the implication of the oxytocinergic system in both major depressive disorder (MDD) and bipolar disorder (BD) and the findings suggest that oxy-related physiological functions change in patients with mood disorders.

In particular, in a post mortem study it has been found that both the number of oxy-producing neurons and oxy mRNA levels within the PVN were increased in patients with MDD (Purba et al., 1996; Meynen et al., 2007). Moreover, the CSF levels of hNPII were higher in bipolar depressed patients compared to healthy controls (Legros et al., 1983; Linkowski et al., 1984), although several studies reported no differences in the CSF hNPII (Linkowski et al., 1984), plasma hNPII (Scantamburlo et al., 2005), CSF oxy (Pitts et al., 1995), or plasma oxy levels (van Londen et al., 1997; Sasayama et al., 2012) in patient with MDD.

In contrast to these findings, Frasch et al. (1995) demonstrated that nocturnal plasma oxy levels were decreased in patient with MDD compared with age-matched controls and that these differences were more pronounced in old than in young patients. On the same line, it has been reported a decrease in serum oxy concentrations in patients with $\mathrm{MDD}$ or $\mathrm{BD}$, compared with healthy controls (Ozsoy et al., 2009).

On the contrary, results obtained from a small study (11 MDD, 19 healthy control patients) reported that oxy plasma concentrations increase during the night in patients with MDD compared to healthy controls. From the observations reported above, it is clear that the results are conflicting and recent studies, performed to elucidate factors that may contribute to these differences across studies, revealed that the dysregulation of oxytocinergic system in MDD may be due to the kind of task used and that any measurement of oxy levels at different time point may lead to conflicting results. For example Scantamburlo et al. (2007) found that oxy levels negatively correlated with Hamilton Depression Rating Scales scores (HAM-D) and anxiety scores on the State-Trait Anxiety Inventory while a positive correlation of oxy plasma levels was found with the Temperament and Character Inventory in outpatients with MDD (Bell et al., 2006). Finally, (Cyranowski et al., 2008) demonstrated that women with MDD showed more variability in oxy release during the different sessions of the task as compared to healthy control group.

The association between the oxyr genetic variations and mood disorders has been studied. In particular adult patients with MDD showed differences in two SNPs within the oxyr gene (Costa et al., 2009) already associated with ASD and a recent study reported for the first time an association between early life stress and symptoms and the oxyr rs139832701 variant (Myers et al., 2014). Multiple studies investigated the response of oxy levels to electroconvulsive therapy (ECT), a standard psychiatric treatment used as a last line of intervention for MDD. All together these studies suggest that the release of oxy and its related carrier protein hNPII could be implicated in the beneficial effect of ECT (Whalley et al., 1982, 1987; Smith et al., 1990, 1994; Scott et al., 1986, 1989, 1991). Although one case report (Scantamburlo et al., 2011) recording the effects of oxy on MDD revealed that 3 weeks intranasal oxy treatment lead to a decrease 
in depressive and anxiety-related symptoms a larger research in this context is necessary.

Several lines of evidence have demonstrated that oxy is an important regulator of anxiety related to physiological stress response; the anxiolytic effect of oxy occurs mainly at the level of PVN and amygdala (Neumann et al., 2000; Bale et al., 2001; Blume et al., 2008; Viviani et al., 2011; Knobloch et al., 2012). Interestingly, a very recent preclinical study revealed that administration od oxy in the central nucleus of the amygdala induces an anxiolytic effects and that this positive effect is abolished by the local pharmacological blockade of oxyrs in this area (László et al., 2015).

In mothers oxy levels positively correlate with sociality, calm, and tolerance (Nissen et al., 1998) and with a less probability of the occurrence of anxiety and stress disorders (Altemus, 1995). Interestingly, during pregnancy and lactation, when oxy levels increase, the mother is protected form anxiety disorders and breastfeeding induces a reduction of stress hormones, as compared with women who bottle-feed their infants (Altemus, 1995). Moreover, women with panic disorder reported a reduction of anxiety symptoms during lactation (Klein et al., 1994-1995) and the anxiolytic action of oxy is enhanced in the presence of circulating oestrogens (McCarthy et al., 1996). Interestingly, intranasal oxy administration reduces amygdala activation, a brain area often dysfunctional in depression and implicated in the biological response to fear (Kirsch et al., 2005). More than one study reported plasma oxy levels in patients with Generalized Social Anxiety Disorder (GSAD). Although social anxiety disorders were associated with an increase of oxy levels, the study from Hoge et al. (2008) reported no significant differences between GSAD and control patients. In another study (Hoge et al., 2012), patients with GSAD had similar plasma oxy levels as compared to controls, but oxy levels were decreased after completing a trust game with a partner. Finally, intranasal oxy administration to patients with GSAD has improved their performance during a speech in front of a group of individuals, and improved mental representations of self (Guastella et al., 2009). In a similar study, a decrease in anxiety symptoms and negative self-appraisals has been found when oxy was administered before an impromptu speech task (Alvares et al., 2012). Finally, a very recent study demonstrated that an oxy analog namely LOT-1, able to penetrate better the $\mathrm{BBB}$ and with long-lasting effect significantly improved anxiety-like behavior and social avoidance in CD157 knockout mouse (a model of non-motor symptoms of Parkinson's disease). Interestingly, LOT-1 had a greater effect on rescue $24 \mathrm{~h}$ from its injection, suggesting that this compound have a longer halflife and a long-lasting effect as compared to oxy (Mizuno et al., 2015).

Among anxiety disorder, OCD is characterized by obsessions and/or compulsions or a combination of such obsessions and compulsions. Oxyrs have been identified in some brain areas, which were linked to the pathophysiology of OCD (Rapoport and Wise, 1988; Modell et al., 1989).

Central oxy administration induces grooming behavior in animals (Witt et al., 1990; Van Erp et al., 1993; Drago et al., 1999), which is considered a model of compulsion as cleaning behavior is a typical symptom displayed by OCD patients (Holzer et al., 1994; Leckman et al., 1994-1995; McDougle et al., 1999). However, the most consistent data regarding the connection between oxytocinergic system and OCD came from the evidence that women display an increased risk to develop a subtype of OCD during pregnancy and the post-partum period, both conditions characterized by elevated levels of oxy (Jenike, 1990; Neziroglu et al., 1992; Sichel et al., 1993). Moreover, adults with OCD showed an increase in oxy CSF levels as well as people affected by the Tourette's syndrome, (Leckman et al., 1994) a neuropsychiatric disorder characterized by multiple physical (motor) and vocal (phonic) tics. However, controversial results have been also published (Altemus et al., 1999) so that more experimental data are necessary to definitely asses the potentiality of oxy (or oxyr antagonists) as anti-obsessional treatment.

\section{Oxytocin and Drug Addiction}

Studies focused on the role of oxy on drug effects and addiction began to emerge in the 1980 (Sarnyai and Kovács, 1994). Since then, theories on the possible involvement of oxy in addiction have begun to receive more and more attention. Interestingly, oxy is released in response to acute 3,4-methylenedioxy-methamphetamine (MDMA, "ecstasy") and methamphetamine administration in both humans (Wolff et al., 2006; Dumont et al., 2009) and animals (Thompson et al., 2007; Broadbear et al., 2011).

In animal studies, oxy was able impede tolerance development to morphine (Kovács and Telegdy, 1987) and dampen the severity of the effects induced by morphine withdrawal (reviewed by Kovács et al., 1998); moreover, oxy administration in rats, leads to a reduction of self-administration of heroin (Kovács and Van Ree, 1985; Kovács et al., 1985; Ibragimov et al., 1987). Oxy attenuates also the hyperactivity due to cocaine use and inhibits the development of tolerance to this drug (Kovàcs et al., 1990; Sarnyai et al., 1992a,b). As far as alcohol, oxy prevents the development of tolerance to ethanol in laboratory mice (Szabó et al., 1989) although it has been demonstrated that acute alcohol administration inhibits oxy secretions while its chronic use is able to stimulate it (Marchesi et al., 1997). Moreover, it has been suggested that oxy might exerts a role in the cognitive dysfunctions observed in alcoholics (Holden et al., 1988; Marchesi et al., 1997). All drugs of abuse increase dopamine release within the mesolimbic system (Pierce and Kumaresan, 2006) and Young and collaborators (Young et al., 2008, 2011) demonstrated the existence of an interaction between oxy and dopaminergic system in both social and drug reward in prairie voles. In particular, the authors showed that methamphetamine was able to reduce pair bonding and pair bonding was able to reduce the rewarding properties of methamphetamine in prairie voles. Interestingly, the interaction occurring within the nucleus accumbens between the mesolimbic dopaminergic and oxytocinergic system was of crucial relevance in this behavior: drugs in prairie voles could reduce dopamine release after social interaction, and social interaction could reduce the reward from drugs. Moreover, it is well known that oxy acts on oxyrs in the medial preoptic area resulting in an 
TABLE 1 | Effects of oxytocin on several behavior in different species.

\begin{tabular}{|c|c|c|c|c|c|}
\hline \multirow[b]{2}{*}{ Behavior } & \multicolumn{5}{|c|}{ Species } \\
\hline & Rat & Mouse & $\begin{array}{l}\text { Parairie } \\
\text { voles }\end{array}$ & Human & References \\
\hline Maternal behavior & $\uparrow$ & $\uparrow$ & $?$ & $\uparrow$ & $\begin{array}{l}\text { Russell et al., 2003; Leng et al., 2005; Ross and } \\
\text { Young, 2009; Bosch and Neumann, } 2012\end{array}$ \\
\hline Sexual behavior & $\uparrow$ & $\leftrightarrow$ & $\begin{array}{l}\downarrow \text { male } \\
\uparrow \text { or } \downarrow \\
\text { female }\end{array}$ & $\uparrow$ & $\begin{array}{l}\text { Carmichael et al., 1987; Carter, 1992; } \\
\text { Anderson-Hunt and Dennerstein, 1994, 1995; Melis } \\
\text { et al., 2007; Baskerville et al., 2009; Gil et al., 2011; } \\
\text { Lazzari et al., } 2013\end{array}$ \\
\hline Social behavior & ? & $\begin{array}{l}\text { prevents deficits in } \\
\text { social behavior and } \\
\text { learning ability }\end{array}$ & ? & $\begin{array}{l}\uparrow \text { retention of social } \\
\text { information and } \\
\text { social communication } \\
\downarrow \text { repetitive behavior }\end{array}$ & $\begin{array}{l}\text { Ferguson et al., 2002; Hollander et al., 2003, 2007; } \\
\text { Kosaka et al., 2012; Tachibana et al., 2013; Teng } \\
\text { et al., 2013; Meziane et al., 2014; Peñagarikano } \\
\text { et al., } 2015\end{array}$ \\
\hline Feeding & $\downarrow$ & $\downarrow$ & $?$ & $\downarrow$ & $\begin{array}{l}\text { Arletti et al., 1989, 1990; Olson et al., 1991; } \\
\text { Kublaoui et al., 2008; Takayanagi et al., 2008; } \\
\text { Maejima et al., 2009, 2011; Deblon et al., 2011; } \\
\text { Dombret et al., 2012; Morton et al., 2012; Ott et al., } \\
\text { 2013; Altirriba et al., 2014; Blevins et al., 2015; } \\
\text { Iwasaki et al., } 2015\end{array}$ \\
\hline $\begin{array}{l}\text { Tolerance to } \\
\text { opiates }\end{array}$ & $\downarrow$ & $\downarrow$ & ? & ? & $\begin{array}{l}\text { Kovàcs et al., 1990; Sarnyai et al., 1992a,b; Kovács } \\
\text { et al., 1998; }\end{array}$ \\
\hline $\begin{array}{l}\text { Tolerance to } \\
\text { ethanol }\end{array}$ & $?$ & $\downarrow$ & $?$ & $?$ & Szabó et al., 1989 \\
\hline
\end{tabular}

The effects of oxytocin on behaviors are indicated as follows: $\uparrow$, increase; $\leftrightarrow$, no effect; $\downarrow$, decrease; ?, unknown (for details, see the indicated references and additional references in the text).

increase of dopamine release from VTA neurons (Champagne et al., 2004; Shahrokh et al., 2010) and this effect is reduced by the administration of an oxyr antagonist in the VTA (Shahrokh et al., 2010); moreover, oxy injections in the VTA leads to an increase of dopamine signal in the NAc (Shahrokh et al., 2010). It would be very interesting to evaluate if this interaction does also exists in humans. Interestingly, Love et al. (2012) have recently shown that oxy gene polymorphisms in humans influence dopaminergic function in a gender-specific manner.

\section{CONCLUSIONS}

A combination between genetic, epigenetic, and environmental factors contributes to originate several neuropsychiatric disorders including ASD, eating disorders, anxiety, depression, and several more. Most of the therapies in use are based on drugs with often limited efficacy and whose mechanisms of action are still not well characterized. Together with classical neurotransmitters, neuropeptidergic signaling is receiving increasing attention since neuropeptides are signaling molecule 
involved in a wide range of brain functions including stress, reward, food intake, metabolism, reproduction, social behaviors, learning, and memory. Although the evidence reviewed here suggests the implication of the oxytocinergic system in several behaviors (Table 1) associated with neuropsychiatric dysfunctions, a number of critical questions still remain to be addressed, in view of a possible drug development along this line. In fact larger, randomized and more controlled trials are needed to better understand the role played

\section{REFERENCES}

Altemus, M. (1995). Neuropeptides in anxiety disorders. Effects of lactation. Ann. N.Y. Acad. Sci. 771, 697-707. doi: 10.1111/j.1749-6632.1995.tb44721.x

Altemus, M., Jacobson, K. R., Debellis, M., Kling, M., Pigott, T., Murphy, D. L., et al. (1999). Normal CSF oxytocin and NPY levels in OCD. Biol. Psychiatry 45, 931-933. doi: 10.1016/S0006-3223(98)00263-7

Altemus, M., Redwine, L. S., Leong, Y. M., Frye, C. A., Porges, S. W., and Carter, C. S. (2001). Responses to laboratory psychosocial stress in postpartum women. Psychosom. Med. 63, 814-821. doi: 10.1097/00006842-20010 9000-00015

Altirriba, J., Poher, A. L., Caillon, A., Arsenijevic, D., Veyrat-Durebex, C., Lyautey, J., et al. (2014). Divergent effects of oxytocin treatment of obese diabetic mice on adiposity and diabetes. Endocrinology 155, 4189-41201. doi: 10.1210/en.20141466

Alvares, G. A., Chen, N. T., Balleine, B. W., Hickie, I. B., and Guastella, A. J. (2012). Oxytocin selectively moderates negative cognitive appraisals in high trait anxious males. Psychoneuroendocrinology 37, 2022-2031. doi: 10.1016/j.psyneuen.2012.04.018

Amar, A. P., and Weiss, M. H. (2003). Pituitary anatomy and physiology. Neurosurg. Clin. N. Am. 14, 11-23. doi: 10.1016/S1042-3680(02)00017-7

Amico, J. A., Challinor, S. M., and Cameron, J. L. (1990). Pattern of oxytocin concentrations in the plasma and cerebrospinal fluid of lactating rhesus monkeys (Macaca mulatta):evidence for functionally independent oxytocinergic pathways in primates. J. Clin. Endocrinol. 71, 1531-1535. doi: 10.1210/jcem-71-6-1531

Amico, J. A., Mantella, R. C., Vollmer, R. R., and Li, X. (2014). Anxiety and stress responses in female oxytocin deficient mice. J. Neuroendocrinol. 16, 319-324. doi: 10.1111/j.0953-8194.2004.01161.x

Anagnostou, E., Soorya, L., Chaplin, W., Bartz, J., Halpern, D., Wasserman, S., et al. (2012). Intranasal oxytocin versus placebo in the treatment of adults with autism spectrum disorders: a randomized controlled trial. Mol. Autism. 3:16. doi: 10.1186/2040-2392-3-16

Andari, E., Duhamel, J. R., Zalla, T., Herbrecht, E., Leboyer, M., and Sirigu, A. (2010). Promoting social behavior with oxytocin in high-functioning autism spectrum disorders. Proc. Natl. Acad. Sci. U.S.A. 107, 4389-4394. doi: 10.1073/pnas.0910249107

Anderberg, U. M., and Uvnäs-Moberg, K. (2000). Plasma oxytocin levels in female fibromyalgia syndrome patients. Z. Rheumatol. 59, 373-379. doi: $10.1007 / \mathrm{s} 003930070045$

Anderson-Hunt, M., and Dennerstein, L. (1994). Increased female sexual response after oxytocin. BMJ 309:929. doi: 10.1136/bmj.309.6959.929

Anderson-Hunt, M., and Dennerstein, L. (1995). Oxytocin and female sexuality. Gynecol. Obstet. Invest. 40, 217-221. doi: 10.1159/000292340

Arletti, R., Benelli, A., and Bertolini, A. (1989). Influence of oxytocin on feeding behavior in the rat. Peptides 10, 89-93. doi: 10.1016/0196-9781(89) 90082-X

Arletti, R., Benelli, A., and Bertolini, A. (1990). Oxytocin inhibits food and fluid intake in rats. Physiol. Behav. 48, 825-830. doi: 10.1016/0031-9384(90)90234-U

Bakharev, V. D., Tikhomirov, S. M., and Lozhkina, T. K. (1986). Psychotropic properties of oxytocin. Neurosci. Behav. Physiol. 16, 160-164. doi: 10.1007/BF01186517

Bale, T. L., Davis, A. M., Auger, A. P., Dorsa, D. M., and McCarthy, M. M. (2001). CNS region-specific oxytocin receptor expression: importance in regulation of by the oxytocinergic system in the pathophysiology of the disorders and the possible use of drugs affecting this system (agonist/antagonist) as novel therapeutic agents in this context.

\section{FUNDING}

We thank MIUR for the grant RBFR12DELS, which covers the post-doctoral fellowship of Dr. AR and of Dr. MM.

anxiety and sex behavior. J. Neurosci. 21, 2546-2552. Available online at: http:// www.jneurosci.org/content/21/7/2546.long

Bales, K. L., Perkeybile, A. M., Conley, O. G., Lee, M. H., Guoynes, C. D., Downing, G. M., et al. (2013). Chronic intranasal oxytocin causes long-term impairments in partner preference formation in male prairie voles. Biol. Psychiatry 74, 180-188. doi: 10.1016/j.biopsych.2012.08.025

Bartz, J. A., Zaki, J., Bolger, N., and Ochsner, K. N. (2011). Social effects of oxytocin in humans: context and person matter. Trends Cogn. Sci. 15, 301-309. doi: 10.1016/j.tics.2011.05.002

Baskerville, T. A., Allard, J., Wayman, C., and Douglas, A. J. (2009). Dopamineoxytocin interactions in penile erection. Eur. J. Neurosci. 30, 2151-2164. doi: 10.1111/j.1460-9568.2009.06999.x

Beckmann, H., Lang, R. E., and Gattaz, W. F. (1985). Vasopressin-oxytocin in cerebrospinal fluid of schizophrenic patients and normal controls. Psychoneuroendocrinology 10, 187-191. doi: 10.1016/0306-4530(85)90056-3

Bell, C. J., Nicholson, H., Mulder, R. T., Luty, S. E., and Joyce, P. R. (2006). Plasma oxytocin levels in depression and their correlation with the temperament dimension of reward dependence. J. Psychopharmacol. 20, 656-660. doi: $10.1177 / 0269881106060512$

Ben-Ari, Y., Gaiarsa, J. L., Tyzio, R., and Khazipov, R. (2007). GABA: a pioneer transmitter that excites immature neurons and generates primitive oscillations. Physiol. Rev. 87, 1215-1284. doi: 10.1152/physrev.00017.2006

Benelli, A., Bertolini, A., Poggioli, R., Menozzi, B., Basaglia, R., and Arletti, R. (1995). Polymodal dose-response curve for oxytocin in the social recognition test. Neuropeptides 28, 251-255. doi: 10.1016/0143-4179(95)90029-2

Bhandari, R., van der Veen, R., Parsons, C. E., Young, K. S., Voorthuis, A., Bakermans-Kranenburg, M. J., et al. (2014). Effects of intranasal oxytocin administration on memory for infant cues: moderation by childhood emotional maltreatment. Soc. Neurosci. 9, 536-547. doi: 10.1080/17470919.2014. 932307

Blanks, A. M., and Thornton, S. (2003). The role of oxytocin in parturition. BJOG 110(Suppl. 20), 46-51. doi: 10.1046/j.1471-0528.2003.00024.x

Blatt, G. J., and Fatemi, S. H. (2011). Alterations in GABAergic biomarkers in the autism brain: research findings and clinical implications. Anat. Rec. (Hoboken) 294, 1646-1452. doi: 10.1002/ar.21252

Blevins, J. E., Graham, J. L., Morton, G. J., Bales, K. L., Schwartz, M. W., Baskin, D. G., et al. (2015). Chronic oxytocin administration inhibits food intake, increases energy expenditure, and produces weight loss in fructose-fed obese rhesus monkeys. Am. J. Physiol. Regul. Integr. Comp. Physiol. 308, R431-R438. doi: 10.1152/ajpregu.00441.2014

Blevins, J. E., and Ho, J. M. (2013). Role of oxytocin signaling in the regulation of body weight. Rev. Endocr. Metab. Disord. 14, 311-329. doi: 10.1007/s11154013-9260-x

Blume, A., Bosch, O. J., Miklos, S., Torner, L., Wales, L., Waldherr, M., et al. (2008). Oxytocin reduces anxiety via ERK1/2 activation: local effect within the rat hypothalamic paraventricular nucleus. Eur. J. Neurosci. 27, 1947-1956. doi: 10.1111/j.1460-9568.2008.06184.x

Bosch, O. J., and Neumann, I. D. (2012). Both oxytocin and vasopressin are mediators of maternal care and aggression in rodents: from central release to sites of action. Horm. Behav. 61, 293-303. doi: 10.1016/j.yhbeh.2011.11.002

Breuil, V., Amri, E. Z., Panaia-Ferrari, P., Testa, J., Elabd, C., AlbertSabonnadière, C., et al. (2011). Oxytocin and bone remodelling: relationships with neuropituitary hormones, bone status and body composition. Joint Bone Spine 78, 611-615. doi: 10.1016/j.jbspin.2011.02.002 
Broadbear, J. H., Tunstall, B., and Beringer, K. (2011). Examining the role of oxytocin in the interoceptive effects of 3,4-methylenedioxymethamphetamine (MDMA, "ecstasy") using a drug discrimination paradigm in the rat. Addict. Biol. 16, 202-214. doi: 10.1111/j.1369-1600.2010.00267.x

Brownstein, M. J., Russell, J. T., and Gainer, H. (1980). Synthesis, transport, and release of posterior pituitary hormones. Science 207, 373-378. doi: $10.1126 /$ science.6153132

Burbach, J. P., Luckman, S. M., Murphy, D., and Gainer, H. (2001). Gene regulation in the magnocellular hypothalamo-neurohypophysial system. Physiol. Rev. 81, 1197-1267. Available online at: http://physrev.physiology.org/content/81/ 3/1197.long

Camerino, C. (2009). Low sympathetic tone and obese phenotype in oxytocindeficient mice. Obesity (Silver Spring) 17, 980-984. doi: 10.1038/oby.2009.12

Campbell, D. B., Datta, D., Jones, S. T., Batey Lee, E., Sutcliffe, J. S., Hammock, E. A., et al. (2011). Association of oxytocin receptor (OXTR) gene variants with multiple phenotype domains of autism spectrum disorder. J. Neurodev. Disord. 3, 101-112. doi: 10.1007/s11689-010-9071-2

Carmichael, M. S., Humbert, R., Dixen, J., Palmisano, G., Greenleaf, W., and Davidson, J. M. (1987). Plasma oxytocin increases in the human sexual response. J. Clin. Endocrinol. Metab. 64, 27-31. doi: 10.1210/jcem-64-1-27

Carson, D. S., Cornish, J. L., Guastella, A. J., Hunt, G. E., and McGregor, I. S. (2010a). Oxytocin decreases methamphetamine self-administration, methamphetamine hyperactivity, and relapse to methamphetamine seeking behaviour in rats. Neuropharmacology 58, 38-43. doi: 10.1016/j.neuropharm.2009.06.018

Carson, D. S., Hunt, G. E., Guastella, A. J., Barber, L., Cornish, J. L., Arnold, J. C., et al. (2010b). Systemically administered oxytocin decreases methamphetamine activation of the subthalamic nucleus and accumbens core and stimulates oxytocinergic neurons in the hypothalamus. Addict. Biol. 15, 448-463. doi: 10.1111/j.1369-1600.2010.00247.x

Carter, C. S. (1992). Oxytocin and sexual behavior. Neurosci. Biobehav. Rev. 16, 131-144. doi: 10.1016/S0149-7634(05)80176-9

Champagne, F. A., Chretien, P., Stevenson, C. W., Zhang, T. Y., Gratton, A., and Meaney, M. J. (2004). Variations in nucleus accumbens dopamine associated with individual differences in maternal behavior in the rat. J. Neurosci. 24, 4113-4123. doi: 10.1523/JNEUROSCI.5322-03.2004

Cicutti, N. J., Smyth, C. E., Rosaeg, O. P., and Wilkinson, M. (1999). Oxytocin receptor binding in rat and human heart. Can. J. Cardiol. 15, 1267-1273.

Condés-Lara, M., Maie, I. A., and Dickenson, A. H. (2005). Oxytocin actions on afferent evoked spinal cord neuronal activities in neuropathic but not in normal rats. Brain Res. 1045, 124-133. doi: 10.1016/j.brainres.2005.03.020

Coote, J. H. (2005). A role for the paraventricular nucleus of the hypothalamus in the autonomic control of heart and kidney. Exp. Physiol. 90, 169-173. doi: 10.1113/expphysiol.2004.029041

Costa, B., Pini, S., Gabelloni, P., Abelli, M., Lari, L., Cardini, A., et al. (2009). Oxytocin receptor polymorphisms and adult attachment style in patients with depression. Psychoneuroendocrinology 34, 1506-1514. doi: 10.1016/j.psyneuen.2009.05.006

Crock, L. W., Kolber, B. J., Morgan, C. D., Sadler, K. E., Vogt, S. K., Bruchas, M. R., et al. (2012). Central amygdala metabotropic glutamate receptor 5 in the modulation of visceral pain. J. Neurosci. 32, 14217-14226. doi: 10.1523/JNEUROSCI.1473-12.2012

Cyranowski, J. M., Hofkens, T. L., Frank, E., Seltman, H., Cai, H. M., and Amico, J. A. (2008). Evidence of dysregulated peripheral oxytocin release among depressed women. Psychosom. Med. 70, 967-975. doi: 10.1097/PSY.0b013e318188ade4

Dabrowska, J., Hazra, R., Ahern, T. H., Guo, J. D., McDonald, A. J., Mascagni, F., et al. (2011). Neuroanatomical evidence for reciprocal regulation of the corticotrophin-releasing factor and oxytocin systems in the hypothalamus and the bed nucleus of the stria terminalis of the rat: Implications for balancing stress and affect. Psychoneuroendocrinology 36, 1312-1326. doi: 10.1016/j.psyneuen.2011.03.003

Dantzer, R., Bluthe, R. M., Koob, G. F., and Le Moal, M. (1987). Modulation of social memory in male rats by neurohypophyseal peptides. Psychopharmacology (Berl). 91, 363-368. doi: 10.1007/BF00518192

Davis, M. C., Green, M. F., Lee, J., Horan, W. P., Senturk, D., Clarke, A. D., et al. (2014). Oxytocin-augmented social cognitive skills training in schizophrenia. Neuropsychopharmacology 39, 2070-2077. doi: 10.1038/npp.2014.68
Deblon, N., Veyrat-Durebex, C., Bourgoin, L., Caillon, A., Bussier, A. L., Petrosino, S., et al. (2011). Mechanisms of the anti-obesity effects of oxytocin in dietinduced obese rats. PLoS ONE 6:e25565. doi: 10.1371/journal.pone.0025565

de Bree, F. M. (2000). Trafficking of the vasopressin and oxytocin prohormone through the regulated secretory pathway. J. Neuroendocrinol. 12, 589-594. doi: 10.1046/j.1365-2826.2000.00521.x

Demitrack, M. A., Lesem, M. D., Listwak, S. J., Brandt, H. A., Jimerson, D. C., and Gold, P. W. (1990). CSF oxytocin in anorexia nervosa and bulimia nervosa: clinical and pathophysiologic considerations. Am. J. Psychiatry 147, 882-886. doi: 10.1176/ajp.147.7.882

Dogterom, J., Van Wimersma Greidanus, T. B., and Swabb, D. F. (1977). Evidence for the release of vasopressin and oxytocin into cerebrospinal fluid: measurements in plasma and CSF of intact and hypophysectomized rats. Neuroendocrinology 24, 108-118. doi: 10.1159/000122702

Dölen, G., Darvishzadeh, A., Huang, K. W., and Malenka, R. C. (2013). Social reward requires coordinated activity of nucleus accumbens oxytocin and serotonin. Nature 501, 179-184. doi: 10.1038/nature12518

Dombret, C., Nguyen, T., Schakman, O., Michaud, J. L., Hardin-Pouzet, H., Bertrand, M. J., et al. (2012). Loss of Maged1 results in obesity, deficits of social interactions, impaired sexual behavior and severe alteration of mature oxytocin production in the hypothalamus. Hum. Mol. Genet. 21, 4703-4717. doi: $10.1093 / \mathrm{hmg} / \mathrm{dds} 310$

Domes, G., Heinrichs, M., Michel, A., Berger, C., and Herpertz, S. C. (2007). Oxytocin improves "mind-reading" in humans. Biol. Psychiatry 61, 731-733. doi: 10.1016/j.biopsych.2006.07.015

Drago, F., Contarino, A., and Busà, L. (1999). The expression of neuropeptide-induced excessive grooming behavior in dopamine D1 and D2 receptor-deficient mice. Eur. J. Pharmacol. 365, 125-131. doi: 10.1016/S0014-2999(98)00877-2

Dumont, G. J., Sweep, F. C., van der Steen, R., Hermsen, R., Donders, A. R., Touw, D. J., et al. (2009). Increased oxytocin concentrations and prosocial feelings in humans after ecstasy (3,4-methylenedioxymethamphetamine) administration. Soc. Neurosci. 4, 359-366. doi: 10.1080/17470910802649470

Dutil, J., Moujahidine, M., Lemieux, C., Jankowski, M., Gutkowska, J., and Deng, A. Y. (2001). Chromosomal and comparative mapping of rat oxytocin, oxytocin receptor and vasopressin genes. Cytogenet. Cell Genet. 93, 57-59. doi: $10.1159 / 000056949$

Dykens, E. M., Leckman, J. F., and Cassidy, S. B. (1996). Obsessions and compulsions in Prader-Willi syndrome. J. Child Psychol. Psychiatry 37, 995-1002. doi: 10.1111/j.1469-7610.1996.tb01496.x

Engelmann, M., Ebner, K., Wotjak, C. T., and Landgraf, R. (1998). Endogenous oxytocin is involved in short-term olfactory memory in female rats. Behav. Brain Res. 90, 89-94. doi: 10.1016/S0166-4328(97)00084-3

Evans, J. J., Reid, R. A., Wakeman, S. A., Croft, L. B., and Benny, P. S. (2003). Evidence that oxytocin is a physiological component of LH regulation in non-pregnant women. Hum. Reprod. 18, 1428-1431. doi: 10.1093/humrep/ $\operatorname{deg} 291$

Favaretto, A. L., Ballejo, G. O., Albuquerque-Araújo, W. I., Gutkowska, J., Antunes-Rodrigues, J., and McCann, S. M. (1997). Oxytocin releases atrial natriuretic peptide from rat atria in vitro that exerts negative inotropic and chronotropic action. Peptides 18, 1377-1381. doi: 10.1016/S01969781(97)00209-X

Feifel, D., Macdonald, K., Cobb, P., and Minassian, A. (2012). Adjunctive intranasal oxytocin improves verbal memory in people with schizophrenia. Schizophr. Res. 139, 207-210. doi: 10.1016/j.schres.2012.05.018

Feifel, D., Macdonald, K., Nguyen, A., Cobb, P., Warlan, H., Galangue, B., et al. (2010). Adjunctive intranasal oxytocin reduces symptoms in schizophrenia patients. Biol. Psychiatry 68, 678-680. doi: 10.1016/j.biopsych.2010.04.039

Ferguson, J. N., Young, L. J., Hearn, E. F., Matzuk, M. M., Insel, T. R., and Winslow, J. T. (2000). Social amnesia in mice lacking the oxytocin gene. Nat. Genet. 25, 284-288. doi: 10.1038/77040

Ferguson, J. N., Young, L. J., and Insel, T. R. (2002). The neuroendocrine basis of social recognition. Front. Neuroendocrinol. 23, 200-224. doi: 10.1006/frne.2002.0229

Francis, S. M., Sagar, A., Levin-Decanini, T., Liu, W., Carter, C. S., and Jacob, S. (2014). Oxytocin and vasopressin systems in genetic syndromes and neurodevelopmental disorders. Brain Res. 1580, 199-218. doi: 10.1016/j.brainres.2014.01.021 
Frasch, A., Zetzsche, T., Steiger, A., and Jirikowski, G. F. (1995). Reduction of plasma oxytocin levels in patients suffering from major depression. Adv. Exp. Med. Biol. 395, 257-258.

Gaida, W., Lang, R. E., Kraft, K., Unger, T., and Ganten, D. (1985). Altered neuropeptide concentrations in spontaneously hypertensive rats: cause or consequence? Clin. Sci. 68, 35-43. doi: 10.1042/cs0680035

Gerdeman, G. L., and Lovinger, D. M. (2003). Emerging roles for endocannabinoids in long-term synaptic plasticity. Br. J. Pharmacol. 140, 781-789. doi: 10.1038/sj.bjp.0705466

Gibson, C. M., Penn, D. L., Smedley, K. L., Leserman, J., Elliott, T., and Pedersen, C. A. (2014). A pilot six-week randomized controlled trial of oxytocin on social cognition and social skills in schizophrenia. Schizophr. Res. 156, 261-265. doi: 10.1016/j.schres.2014.04.009

Gigliucci, V., Leonzino, M., Busnelli, M., Luchetti, A., Palladino, V. S., D'Amato, F. R., et al. (2014). Region specific up-regulation of oxytocin receptors in the opioid oprm1 (-/-) mouse model of autism. Front. Pediatr. 2:91. doi: 10.3389/fped.2014.00091

Gil, M., Bhatt, R., Picotte, K. B., and Hull, E. M. (2011). Oxytocin in the medial preoptic area facilitates male sexual behavior in the rat. Horm. Behav. 59, 435-443. doi: 10.1016/j.yhbeh.2010.12.012

Gimpl, G., and Fahrenholz, F. (2001). The oxytocin receptor system: structure, function, and regulation. Physiol. Rev. 81, 629-683. Available online at: http:// physrev.physiology.org/content/81/2/629.long

Glovinsky, D., Kalogeras, K. T., Kirch, D. G., Suddath, R., and Wyatt, R. J. (1994). Cerebrospinal fluid oxytocin concentration in schizophrenic patients does not differ from control subjects and is not changed by neuroleptic medication. Schizophr. Res. 11, 273-276. doi: 10.1016/0920-9964(94) 90021-3

Gogolla, N., Leblanc, J. J., Quast, K. B., Südhof, T. C., Fagiolini, M., and Hensch, T. K. (2009). Common circuit defect of excitatory-inhibitory balance in mouse models of autism. J. Neurodev. Disord. 2, 172-181. doi: 10.1007/s11689-0099023-x

Goldman, M. B., Gomes, A. M., Carter, C. S., and Lee, R. (2011). Divergent effects of two different doses of intranasal oxytocin on facial affect discrimination in schizophrenic patients with and without polydipsia. Psychopharmacology (Berl). 216, 101-110. doi: 10.1007/s00213-011-2193-8

Goldman, M., Marlow-O'Connor, M., Torres, I., and Carter, C. S. (2008). Diminished plasma oxytocin in schizophrenic patients with neuroendocrine dysfunction and emotional deficits. Schizophr. Res. 98, 247-255. doi: 10.1016/j.schres.2007.09.019

Green, L., Fein, D., Modahl, C., Feinstein, C., Waterhouse, L., and Morris, M. (2001). Oxytocin and autistic disorder: alterations in peptide forms. Biol. Psychiatry 50, 609-613. doi: 10.1016/S0006-3223(01)01139-8

Gregory, S. G., Connelly, J. J., Towers, A. J., Johnson, J., Biscocho, D., Markunas, C. A., et al. (2009). Genomic and epigenetic evidence for oxytocin receptor deficiency in autism. BMC Med. 7:62. doi: 10.1186/1741-7015-7-62

$\mathrm{Gu}, \mathrm{X}$. L., and Yu, L. C. (2007). Involvement of opioid receptors in oxytocininduced antinociception in the nucleus accumbens of rats. J. Pain 8, 85-90. doi: 10.1016/j.jpain.2006.07.001

Guastella, A. J., Einfeld, S. L., Gray, K. M., Rinehart, N. J., Tonge, B. J., Lambert, T. J., et al. (2010). Intranasal oxytocin improves emotion recognition for youth with autism spectrum disorders. Biol. Psychiatry 67, 692-694. doi: 10.1016/j.biopsych.2009.09.020

Guastella, A. J., Howard, A. L., Dadds, M. R., Mitchell, P., and Carson, D. S. (2009). A randomized controlled trial of intranasal oxytocin as an adjunct to exposure therapy for social anxiety disorder. Psychoneuroendocrinology 34, 917-923. doi: 10.1016/j.psyneuen.2009.01.005

Gutkowska, J., Jankowski, M., Lambert, C., Mukaddam-Daher, S., Zingg, H. H., and McCann, S. M. (1997). Oxytocin releases atrial natriuretic peptide by combining with oxytocin receptors in the heart. Proc. Natl. Acad. Sci. U.S.A. 94, 11704-11709. doi: 10.1073/pnas.94.21.11704

Hammock, E. A., and Levitt, P. (2013). Oxytocin receptor ligand binding in embryonic tissue and postnatal brain development of the C57BL/6J mouse. Front. Behav. Neurosci. 7:195. doi: 10.3389/fnbeh. 2013.00195

Han, Y., and Yu, L. C. (2009). Involvement of oxytocin and its receptor in nociceptive modulation in the central nucleus of amygdala of rats. Neurosci. Lett. 454, 101-104. doi: 10.1016/j.neulet.2009.02.062
Harris, M. C., Jones, P. M., and Robinson, I. C. (1981). Differences in the release of oxytocin into the blood and cerebrospinal fluid following hypothalamic and pituitary stimulation in rats. J. Physiol. 320, 109-110.

Hoge, E. A., Lawson, E. A., Metcalf, C. A., Keshaviah, A., Zak, P. J., Pollack, M. H., et al. (2012). Plasma oxytocin immunoreactive products and response to trust in patients with social anxiety disorder. Depress. Anxiety. 29, 924-930. doi: 10.1002/da.21973

Hoge, E. A., Pollack, M. H., Kaufman, R. E., Zak, P. J., and Simon, N. M. (2008). Oxytocin levels in social anxiety disorder. CNS Neurosci. Ther. 14, 165-170. doi: 10.1111/j.1755-5949.2008.00051.x

Holden, K. L., McLaughlin, E. J., Reilly, E. L., and Overall, J. E. (1988). Accelerated mental aging in alcoholic patients. J. Clin. Psychol. 44, 286-292.

Holder, J. L. Jr., Butte, N. F., and Zinn, A. R. (2000). Profound obesity associated with a balanced translocation that disrupts the SIM1 gene. Hum. Mol. Genet. 9, 101-108. doi: 10.1093/hmg/9.1.101

Hollander, E., Bartz, J., Chaplin, W., Phillips, A., Sumner, J., Soorya, L., et al. (2007). Oxytocin increases retention of social cognition in autism. Biol. Psychiatry 61, 498-503. doi: 10.1016/j.biopsych.2006.05.030

Hollander, E., Novotny, S., Hanratty, M., Yaffe, R., DeCaria, C. M., Aronowitz, B. R., et al. (2003). Oxytocin infusion reduces repetitive behaviors in adults with autistic and Asperger's disorders. Neuropsychopharmacology 1, 193-198. doi: 10.1038/sj.npp. 1300021

Holzer, J. C., Goodman, W. K., McDougle, C. J., Baer, L., Boyarsky, B. K., Leckman, J. F., et al. (1994). Obsessive-compulsive disorder with and without a chronic tic disorder. A comparison of symptoms in 70 patients. Br. J. Psychiatry 164, 469-473. doi: 10.1192/bjp.164.4.469

Huang, H., Michetti, C., Busnelli, M., Managò, F., Sannino, S., Scheggia, E., et al. (2014). Chronic and acute intranasal oxytocin produce divergent social effects in mice. Neuropsychopharmacology 39, 1102-1114. doi: 10.1038/npp. 2013.310

Ibragimov, R., Kovács, G. L., Szabó, G., and Telegdy, G. (1987). Microinjection of oxytocin into limbic-mesolimbic brain structures disrupts heroin selfadministration behavior: a receptor-mediated event? Life Sci. 41, 1265-1271. doi: 10.1016/0024-3205(87)90205-0

Insel, T. R., and Fernald, R. D. (2004). How the brain processes social information: searching for the social brain. Annu. Rev. Neurosci. 27, 697-722. doi: 10.1146/annurev.neuro.27.070203.144148

Insel, T. R., and Hulihan, T. J. (1995). A gender-specific mechanism for pair bonding: oxytocin and partner preference formation in monogamous voles. Behav. Neurosci. 109, 782-789. doi: 10.1037/0735-7044.109.4.782

Insel, T. R., O'Brien, D. J., and Leckman, J. F. (1999). Oxytocin, vasopressin, and autism: is there a connection? Biol. Psychiatry 45, 145-157. doi: 10.1016/S00063223(98)00142-5

Insel, T. R., and Young, L. J. (2001). The neurobiology of attachment. Nat. Rev. Neurosci. 2, 129-136. doi: 10.1038/35053579

Ivell, R., and Richter, D. (1984). Structure and comparison of the oxytocin and vasopressin genes from rat. Proc. Natl. Acad. Sci. U.S.A. 81, 2006-2010. doi: 10.1073/pnas.81.7.2006

Iwasaki, Y., Maejima, Y., Suyama, S., Yoshida, M., Arai, T., Katsurada, K., et al. (2015). Peripheral oxytocin activates vagal afferent neurons to suppress feeding in normal and leptin-resistant mice: a route forameliorating hyperphagia and obesity. Am. J. Physiol. Regul. Integr. Comp. Physiol. 308, R360-R369. doi: 10.1152/ajpregu.00344.2014

Jacob, S., Brune, C. W., Carter, C. S., Leventhal, B. L., Lord, C., Cook, E. H., et al. (2007). Association of the oxytocin receptor gene (OXTR) in caucasian children and adolescents with autism. Neurosci. Lett. 417, 6-9. doi: 10.1016/j.neulet.2007.02.001

Jankowski, M., Hajjar, F., Kawas, S. A., Mukaddam-Daher, S., Hoffman, G., McCann, S. M., et al. (1998). Rat heart: a site of oxytocin production and action. Proc. Natl. Acad. Sci. U.S.A. 95, 14558-14563. doi: 10.1073/pnas.95.24.14558

Jankowski, M., Wang, D., Hajjar, F., Mukaddam-Daher, S., McCann, S. M., and Gutkowska, J. (2000). Oxytocin and its receptors are synthesized in the rat vasculature. Proc. Natl. Acad. Sci. U.S.A. 97, 6207-6211. doi: 10.1073/pnas. 110137497

Jansen, L. M., Gispen-de Wied, C. C., Wiegant, V. M., Westenberg, H. G., Lahuis, B. E., and van Engeland, H. (2006). Autonomic and neuroendocrine responses to a psychosocial stressor in adults with autistic spectrum disorder. J. Autism Dev. Disord. 36, 891-899. doi: 10.1007/s10803-006-0124-z 
Jenike, M. A. (1990). Obsessive-Compulsive Disorders in Pregnancy and Childbirth. Littleton: Year Book Medical.

Johnstone, L. E., Fong, T. M., and Leng, G. (2006). Neuronal activation in the hypothalamus and brainstem during feeding in rats. Cell Metab. 4, 313-321. doi: 10.1016/j.cmet.2006.08.003

Jones, P. M., and Robinson, I. C. (1982). Differential clearance of neurophysin and neurohypophysial peptides from the cerebrospinal fluid in conscious guinea pigs. Neuroendocrinology 34, 297-302. doi: 10.1159/000123316

Kasama, S., Furuya, M., Toyama, T., Ichikawa, S., and Kurabayashi, M. (2008). Effect of atrial natriuretic peptide on left ventricular remodelling in patients with acute myocardial infarction. Eur. Heart J. 29, 1485-1494. doi: 10.1093/eurheartj/ehn206

Kimura, T., Tanizawa, O., Mori, K., Brownstein, M. J., and Okayama, H. (1992). Structure and expression of a human oxytocin receptor. Nature 356, 526-529. doi: $10.1038 / 356526 \mathrm{a} 0$

Kirsch, P., Esslinger, C., Chen, Q., Mier, D., Lis, S., Siddhanti, S., et al. (2005). Oxytocin modulates neural circuitry for social cognition and fear in humans. J. Neurosci. 25, 11489-11493. doi: 10.1523/JNEUROSCI.3984-05.2005

Kiss, A., Bundzikova, J., Pirnik, Z., and Mikkelsen, J. D. (2010). Different antipsychotics elicit different effects on magnocellular oxytocinergic and vasopressinergic neurons as revealed by Fos immunohistochemistry. J. Neurosci. Res. 88, 677-685. doi: 10.1002/jnr.22226

Klein, D. F., Skrobala, A. M., and Garfinkel, R. S. (1994-1995). Preliminary look at the effects of pregnancy on the course of panic disorder. Anxiety 1 , 227-232.

Knobloch, H. S., Charlet, A., Hoffmann, L. C., Eliava, M., Khrulev, S., Cetin, A. H., et al. (2012). Evoked axonal oxytocin release in the central amygdala attenuates fear response. Neuron 73, 553-566. doi: 10.1016/j.neuron.2011.11.030

Kosaka, H., Munesue, T., Ishitobi, M., Asano, M., Omori, M., Sato, M., et al. (2012). Long-term oxytocin administration improves social behaviors in a girl with autistic disorder. BMC Psychiatry 12:110. doi: 10.1186/1471-244X-12-110

Kovács, C. L., and Van Ree, J. M. (1985). Behaviorally active oxytocin fragments simultaneously attenuate heroin self-administration and tolerance in rats. Life Sci. 37, 1895-1900. doi: 10.1016/0024-3205(85)90007-4

Kovács, G. L., Borthaiser, Z., and Telegdy, G. (1985). Oxytocin reduces intravenous heroin self-administration in heroin-tolerant rats. Life Sci. 37, 17-26. doi: 10.1016/0024-3205(85)90620-4

Kovàcs, G. L., Sarnyai, Z., Barbarczi, E., Szabó, G., and Telegdy, G. (1990). The role of oxytocin-dopamine interactions in cocaine-induced locomotor hyperactivity. Neuropharmacology 29, 365-368. doi: 10.1016/00283908(90)90095-9

Kovács, G. L., Sarnyai, Z., and Szabó, G. (1998). Oxytocin and addiction: a review. Psychoneuroendocrinology 23, 945-962. doi: 10.1016/S0306-4530(98)00064-X

Kovács, G. L., and Telegdy, G. (1987). Beta-endorphin tolerance is inhibited by oxytocin. Pharmacol. Biochem. Behav. 26, 57-60. doi: 10.1016/00913057(87) $90533-8$

Kublaoui, B. M., Gemelli, T., Tolson, K. P., Wang, Y., and Zinn, A. R. (2008). Oxytocin deficiency mediates hyperphagic obesity of Sim1 haploinsufficient mice. Mol. Endocrinol. 22, 1723-1734. doi: 10.1210/me. 2008-0067

Labuschagne, I., Phan, K. L., Wood, A., Angstadt, M., Chua, P., Heinrichs, M., et al. (2010). Oxytocin attenuates amygdala reactivity to fear in generalized social anxiety disorder. Neuropsychopharmacology 35, 2403-2413. doi: $10.1038 / \mathrm{npp} .2010 .123$

Landgraf, R., and Neumann, I. D. (2004). Vasopressin and oxytocin release within the brain: a dynamic concept of multiple and variable modes of neuropeptide communication. Front. Neuroendocrinol. 25, 150-176. doi: 10.1016/j.yfrne.2004.05.001

László, K., Kovács, A., Zagoracz, O., Ollmann, T., Péczely, L., Kertes, E., et al. (2015). Positive reinforcing effect of oxytocin microinjection in the rat central nucleus of amygdala. Behav. Brain Res. 296, 279-285. doi: 10.1016/j.bbr.2015.09.021

Lawson, E. A., Donoho, D. A., Blum, J. I., Meenaghan, E. M., Misra, M., Herzog, D. B., et al. (2011). Decreased nocturnal oxytocin levels in anorexia nervosa are associated with low bone mineral density and fat mass. J. Clin. Psychiatry 72 , 1546-1551. doi: 10.4088/JCP.10m06617

Lazzari, V. M., Becker, R. O., de Azevedo, M. S., Morris, M., Rigatto, K., Almeida, S., et al. (2013). Oxytocin modulates social interaction but is not essential for sexual behavior in male mice. Behav. Brain Res. 1, 130-136. doi: 10.1016/j.bbr.2013.01.025

Leckman, J. F., Goodman, W. K., North, W. G., Chappell, P. B., Price, L. H., Pauls, D. L., et al. (1994). Elevated cerebrospinal fluid levels of oxytocin in obsessive-compulsive disorder. Comparison with Tourette's syndrome and healthy controls. Arch. Gen. Psychiatry 51, 782-792. doi: 10.1001/archpsyc.1994.03950100030003

Leckman, J. F., Grice, D. E., Barr, L. C., de Vries, A. L., Martin, C., Cohen, D. J., et al. (1994-1995). Tic-related vs. non-tic-related obsessive compulsive disorder. Anxiety 1, 208-215.

Legros, J. J., Gazzotti, C., Carvelli, T., Franchimont, P., Timsit-Berthier, M., von Frenckell, R., et al. (1992). Apomorphine stimulation of vasopressin- and oxytocin-neurophysins. Evidence for increased oxytocinergic and decreased vasopressinergic function in schizophrenics. Psychoneuroendocrinology 17 , 611-617. doi: 10.1016/0306-4530(92)90019-4

Legros, J. J., and Geenen, V. (1996). Neurophysins in central diabetes insipidus. Horm. Res. 45, 182-186. doi: 10.1159/000184784

Legros, J. J., Geenen, V., Linkowski, P., and Mendlewicz, J. (1983). Increased neurophysin I and II cerbrospinal fluid concentration from bipolar versus unipolar depressed patients. Neuroendocrinol. Lett. 5, 201-205.

Leng, G., Caquineau, C., and Sabatier, N. (2005). Regulation of oxytocin secretion. Vitam. Horm. 71, 27-58. doi: 10.1016/S0083-6729(05)71002-5

Lerer, E., Levi, S., Salomon, S., Darvasi, A., Yirmiya, N., and Ebstein, R. P. (2008). Association between the oxytocin receptor (OXTR) gene and autism: Relationship to vineland adaptive behavior scales and cognition. Mol. Psychiatry 13, 980-988. doi: 10.1038/sj.mp.4002087

Linkowski, P., Geenen, V., Kerkhofs, M., Mendlewicz, J., and Legros, J. J. (1984). Cerebrospinal fluid neurophysins in affective illness and in schizophrenia. Eur. Arch. Psychiatry Neurol. Sci. 234, 162-165. doi: 10.1007/BF00461555

Lord, C., Rutter, M., and Le Couteur, A. (1994). Autism Diagnostic InterviewRevised: a revised version of a diagnostic interview for caregivers of individuals with possible pervasive developmental disorders. J. Autism Dev. Disord. 24, 659-685. doi: 10.1007/BF02172145

Love, T. M., Enoch, M. A., Hodgkinson, C. A., Peciña, M., Mickey, B., Koeppe, R. A., et al. (2012). Oxytocin gene polymorphisms influence human dopaminergic function in a sex-dependent manner. Biol. Psychiatry 72, 198-206. doi: 10.1016/j.biopsych.2012.01.033

Ludwig, M. (1998). Dendritic release of vasopressin and oxytocin J. Neuroendocrinol. 10, 881-895. doi: 10.1046/j.1365-2826.1998.00279.x

Ludwig, M., and Leng, G. (2006). Dendritic peptide release and peptidedependentbehaviours. Nat. Rev. Neurosci. 7, 126-136. doi: 10.1038/nrn1845

Lukas, M., Toth, I., Veenema, A. H., and Neumann, I. D. (2013). Oxytocin mediates rodent social memory within the lateral septum and the medial amygdala depending on the relevance of the social stimulus: male juvenile versus female adult conspecifics. Psychoneuroendocrinology 38, 916-926. doi: 10.1016/j.psyneuen.2012.09.018

Lundeberg, T., Meister, B., Björkstrand, E., and Uvnas-Moberg, K. (1993). Oxytocin modulates the effects of galanin in carrageenan-induced hyperalgesia in rats. Brain Res. 608, 181-185. doi: 10.1016/0006-8993(93)91456-3

Macdonald, K., and Feifel, D. (2012). Oxytocin in schizophrenia: a review of evidence for its therapeutic effects. Acta Neuropsychiatr. 24, 130-146. doi: 10.1111/j.1601-5215.2011.00634.X

Maejima, Y., Iwasaki, Y., Yamahara, Y., Kodaira, M., Sedbazar, U., and Yada, T. (2011). Peripheral oxytocin treatment ameliorates obesity by reducing food intake and visceral fat mass. Aging (Albany NY) 3, 1169-1177. doi: $10.1155 / 2010 / 289645$

Maejima, Y., Sedbazar, U., Suyama, S., Kohno, D., Onaka, T., Takano, E., et al. (2009). Nesfatin-1-regulated oxytocinergic signaling in the paraventricular nucleus causes anorexia through a leptin independent melanocortin pathway. Cell Metab. 10, 355-365. doi: 10.1016/j.cmet.2009.09.002

Maes, M., Monteleone, P., Bencivenga, R., Goossens, F., Maj, M., van West, D., et al. (2001). Lower serum activity of prolyl endopeptidase in anorexia and bulimia nervosa. Psychoneuroendocrinology 26, 17-26. doi: 10.1016/S03064530(00)00032-9

Maguire, S., O'Dell, A., Touyz, L., and Russell, J. (2013). Oxytocin and anorexia nervosa: a review of the emerging literature. Eur. Eat. Disord. Rev. 21, 475-478. doi: $10.1002 /$ erv.2252 
Marazziti, D., and Catena Dell'osso, M. (2008). The role of oxytocin in neuropsychiatric disorders. Curr. Med. Chem. 15, 698-704. doi: $10.2174 / 092986708783885291$

Marchesi, C., Chiodera, P., Brusamonti, E., Volpi, R., and Coiro, V. (1997). Abnormal plasma oxytocin and beta-endorphin levels in alcoholics after short and long term abstinence. Prog. Neuropsychopharmacol. Biol. Psychiatry 21, 797-807. doi: 10.1016/S0278-5846(97)00080-8

Marlin, B. J., Mitre, M., D’amour, J. A., Chao, M. V., and Froemke, R. C. (2015). Oxytocin enables maternal behaviour by balancing cortical inhibition. Nature 520, 499-504. doi: 10.1038/nature14402

Matsuura, K., Nagai, T., Nishigaki, N., Oyama, T., Nishi, J., Wada, H., et al. (2004). Adult cardiac Sca-1-positive cells differentiate into beating cardiomyocytes. J. Biol. Chem. 279, 11384-11391. doi: 10.1074/jbc.M310822200

Mazzuca, M., Minlebaev, M., Shakirzyanova, A., Tyzio, R., Taccola, G., Janackova, S., et al. (2011). Newborn analgesia mediated by oxytocin during delivery. Front. Cell. Neurosci. 5:3. doi: 10.3389/fncel.2011.00003

McCann, M. J., and Rogers, R. C. (1990). Oxytocin excites gastric-related neurones in rat dorsal vagal complex. J. Physiol. (Lond). 428, 95-108. doi: 10.1113/jphysiol.1990.sp018202

McCarthy, M. M., McDonald, C. H., Brooks, P. J., and Goldman, D. (1996). An anxiolytic action of oxytocin is enhanced by estrogen in the mouse. Physiol. Behav. 60, 1209-1215. doi: 10.1016/S0031-9384(96)00212-0

McDougle, C. J., Barr, L. C., Goodman, W. K., and Price, L. H. (1999). Possible role of neuropeptides in obsessive compulsive disorder. Psychoneuroendocrinology 24, 1-24. doi: 10.1016/S0306-4530(98)00046-8

Melis, M. R., Melis, T., Cocco, C., Succu, S., Sanna, F., Pillolla, G., et al. (2007). Oxytocin injected into the ventral tegmental area induces penile erection and increases extracellular dopamine in the nucleus accumbens and paraventricular nucleus of the hypothalamus of male rats. Eur. J. Neurosci. 26, 1026-1035. doi: 10.1111/j.1460-9568.2007.05721.x

Mens, W. B., Laczi, F., Tonnaer, J. A., de Kloet, E. R., and van Wimersma Greidanus, T. B. (1983). Vasopressin and oxytocin content in cerebrospinal fluid and in various brain areas after administration of histamine and pentylenetetrazol. Pharmacol. Biochem. Behav. 19, 587-591. doi: 10.1016/00913057(83)90332-5

Meyer, C., Freund-Mercier, M. J., Guerné, Y., and Richard, P. (1987). Relationship between oxytocin release and amplitude of oxytocin cell neurosecretory bursts during suckling in the rat. J. Endocrinol. 114, 263-270. doi: $10.1677 /$ joe. 0.1140263

Meynen, G., Unmehopa, U. A., Hofman, M. A., Swaab, D. F., and Hoogendijk, W. J. (2007). Hypothalamic oxytocin mRNA expression and melancholic depression. Mol. Psychiatry 12, 118-119. doi: 10.1038/sj.mp.4001911

Meziane, H., Schaller, F., Bauer, S., Villard, C., Matarazzo, V., Riet, F., et al. (2014). An early postnatal oxytocin treatment prevents social and learning deficits in adult mice deficient for Magel2, a gene involved in Prader-Willi Syndrome and autism. Biol. Psychiatry 78, 85-94. doi: 10.1016/j.biopsych. 2014.11.010

Mizuno, A., Cherepanov, S. M., Kikuchi, Y., Fakhrul, A. A., Akther, S., Deguchi, K., et al. (2015). Lipo-oxytocin-1, a novel oxytocin analog conjugated with two palmitoyl groups, has long-lasting effects on anxiety-related behavior and social avoidance in CD157 knockout mice. Brain Sci. 5, 3-13. doi: 10.3390/brainsci5010003

Modabbernia, A., Rezaei, F., Salehi, B., Jafarinia, M., Ashrafi, M., Tabrizi, M., et al. (2013). Intranasal oxytocin as an adjunct to risperidone in patients with schizophrenia: an 8-week, randomized, double-blind, placebo-controlled study. CNS Drugs 27, 57-65. doi: 10.1007/s40263-012-0022-1

Modahl, C., Green, L., Fein, D., Morris, M., Waterhouse, L., Feinstein, C., et al. (1998). Plasma oxytocin levels in autistic children. Biol. Psychiatry 43, 270-277. doi: 10.1016/S0006-3223(97)00439-3

Modell, J. G., Mountz, J. M., Curtis, G. C., and Greden, J. F. (1989). Neurophysiologic dysfunction in basal ganglia/limbic striatal and thalamocortical circuits as a pathogenetic mechanism of obsessive-compulsive disorder. J. Neuropsychiatry Clin. Neurosci. 1, 27-36. doi: 10.1176/jnp.1.1.27

Montag, C., Brockmann, E. M., Bayerl, M., Rujescu, D., Müller, D. J., and Gallinat, J. (2013). Oxytocin and oxytocin receptor gene polymorphisms and risk for schizophrenia: a case-control study. World J. Biol. Psychiatry 14, 500-508. doi: $10.3109 / 15622975.2012 .677547$
Morris, J. F., and Pow, D. V. (1991). Widespread release of peptides in the central nervous system: quantitation of tannic acid-captured exocytoses. Anat. Rec. 231, 437-445. doi: 10.1002/ar.1092310406

Morton, G. J., Thatcher, B. S., Reidelberger, R. D., Ogimoto, K., WoldenHanson, T., Baskin, D. G., et al. (2012). Peripheral oxytocin suppresses food intake and causes weight loss in diet-induced obese rats. Am. J. Physiol. Endocrinol. Metab. 302, E134-E144. doi: 10.1152/ajpendo.00296.2011

Moy, S. S., Nadler, J. J., Young, N. B., Perez, A., Holloway, L. P., Barbaro, R. P., et al. (2007). Mouse behavioural tasks relevant to autism: phenotypes of 10 inbred strains. Behav. Brain Res. 176, 4-20. doi: 10.1016/j.bbr.2006.07.030

Muchmore, D. B., Little, S. A., and de Haën, C. (1981). A dual mechanism of action of ocytocin in rat epididymal fat cells. J. Biol. Chem. 256, 365-372.

Muhle, R., Trentacoste, S. V., and Rapin, I. (2004). The genetics of autism. Pediatrics 113, e472-e486. doi: 10.1542/peds.113.5.e472

Mühlethaler, M., Charpak, S., and Dreifuss, J. J. (1984). Contrasting effects of neurohypophysial peptides on pyramidal and non-pyramidal neurones in the rat hippocampus. Brain Res. 308, 97-107. doi: 10.1016/0006-8993(84)90921-1

Muscatelli, F., Abrous, D. N., Massacrier, A., Boccaccio, I., Le Moal, M., Cau, P., et al. (2000). Disruption of the mouse Necdin gene results in hypothalamic and behavioural alterations reminiscent of the human Prader-Willi syndrome. Hum. Mol. Genet. 9, 3101-3110. doi: 10.1093/hmg/9.20.3101

Myers, A. J., Williams, L., Gatt, J. M., McAuley-Clark, E. Z., Dobson-Stone, C., Schofield, P. R., et al. (2014). Variation in the oxytocin receptor gene is associated with increased risk for anxiety, stress and depression in individuals with a history of exposure to early life stress. J. Psychiatr. Res. 59, 93-100. doi: 10.1016/j.jpsychires.2014.08.021

Nelson, E. E., Alberts, J. R., Tian, Y., and Verbalis, J. G. (1998). Oxytocin is elevated in plasma of 10-day-old rats following gastric distension. Brain Res. Dev. Brain Res. 111, 301-303. doi: 10.1016/S0165-3806(98)00147-3

Neumann, I., Douglas, A. J., Pittman, Q. J., Russell, J. A., and Landgraf, R. (1996). Oxytocin released within the supraoptic nucleus of the rat brain by positive feedback action is involved in parturition-related events. J. Neuroendocrinol. 8 , 227-233. doi: 10.1046/j.1365-2826.1996.04557.x

Neumann, I. D., Torner, L., and Wigger, A. (2000). Brain oxytocin: differential inhibition of neuroendocrine stress responses and anxiety-related behaviour in virgin, pregnant and lactating rats. Neuroscience 95, 567-575. doi 10.1016/S0306-4522(99)00433-9

Neziroglu, F., Anemone, R., and Yaryura-Tobias, J. A. (1992). Onset of obsessivecompulsive disorder in pregnancy. Am. J. Psychiatry 149, 947-950. doi: 10.1176/ajp.149.7.947

Nissen, E., Gustavsson, P., Widström, A. M., and Uvnäs-Moberg, K. (1998). Oxytocin, prolactin, milk production and their relationship with personality traits in women after vaginal delivery or Cesarean section. J. Psychosom. Obstet. Gynaecol. 19, 49-58. doi: 10.3109/01674829809044221

Olff, M., Frijling, J. L., Kubzansky, L. D., Bradley, B., Ellenbogen, M. A., Cardoso, C., et al. (2013). The role of oxytocin in social bonding, stress regulation and mental health: an update on the moderating effects of context and interindividual differences. Psychoneuroendocrinology 38, 1883-1894. doi: 10.1016/j.psyneuen.2013.06.019

Olson, B. R., Drutarosky, M. D., Chow, M. S., Hruby, V. J., Stricker, E. M., and Verbalis, J. G. (1991). Oxytocin and an oxytocin agonist administered centrally decrease food intake in rats. Peptides 199, 113-118. doi: 10.1016/01969781(91)90176-P

Olson, B. R., Hoffman, G. E., Sved, A. F., Stricker, E. M., and Verbalis, J. G. (1992). Cholecystokinin induces c-fos expression in hypothalamic oxytocinergic neurons projecting to the dorsal vagal complex. Brain Res. 569, 238-248. doi: 10.1016/0006-8993(92)90635-M

Onaka, T. (2004). Neural pathways controlling central and peripheral oxytocin release during stress. J. Neuroendocrinol. 16, 308-312. doi: 10.1111/j.09538194.2004.01186.x

Ondrejcakova, M., Ravingerova, T., Bakos, J., Pancza, D., and Jezova, D. (2009). Oxytocin exerts protective effects on in vitro myocardial injury induced by ischemia and reperfusion. Can. J. Physiol. Pharmacol. 87, 137-142. doi: 10.1139/Y08-108

Ott, V., Finlayson, G., Lehnert, H., Heitmann, B., Heinrichs, M., Born, J., et al. (2013). Oxytocin reduces reward-driven food intake in humans. Diabetes 62, 3418-3425, doi: 10.2337/db13-0663 
Owen, S. F., Tuncdemir, S. N., Bader, P. L., Tirko, N. N., Fishell, G., and Tsien, R. W. (2013). Oxytocin enhances hippocampal spike transmission by modulating fast-spiking interneurons. Nature 500, 458-462. doi: 10.1038/nature 12330

Oyama, T., Nagai, T., Wada, H., Naito, A. T., Matsuura, K., Iwanaga, K., et al. (2007). Cardiac side population cells have a potential to migrate and differentiate into cardiomyocytes in vitro and in vivo. J. Cell Biol. 176, 329-341. doi: $10.1083 /$ jcb. 200603014

Ozsoy, S., Esel, E., and Kula, M. (2009). Serum oxytocin levels in patients with depression and the effects of gender and antidepressant treatment. Psychiatry Res. 169, 249-252. doi: 10.1016/j.psychres.2008.06.034

Page, S. R., Ang, V. T., Jackson, R., White, A., Nussey, S. S., and Jenkins, J. S. (1990). The effect of oxytocin infusion on adenohypophyseal function in man. Clin. Endocrinol. (Oxf). 32, 307-313. doi: 10.1111/j.1365-2265.1990.tb00871.x

Peñagarikano, O., Lázaro, M. T., Lu, X. H., Gordon, A., Dong, H., Lam, H. A., et al. (2015). Exogenous and evoked oxytocin restores social behavior in the Cntnap2 mouse model of autism. Sci. Transl. Med. 7:271ra8. doi: 10.1126/scitranslmed.3010257

Petersson, M., Alster, P., Lundeberg, T., and Uvnäs-Moberg, K. (1996). Oxytocin causes a long-term decrease of blood pressure in female and male rats. Physiol. Behav. 60, 1311-1315. doi: 10.1016/S0031-9384(96) 00261-2

Pierce, R. C., and Kumaresan, V. (2006). The mesolimbic dopamine system: the final common pathway for the reinforcing effect of drugs of abuse? Neurosci. Biobehav. Rev. 30, 215-238. doi: 10.1016/j.neubiorev. 2005.04.016

Pierrehumbert, B., Torrisi, R., Laufer, D., Halfon, O., Ansermet, F., and Beck Popovic, M. (2010). Oxytocin response to an experimental psychosocial challenge in adults exposed to traumatic experiences during childhood or adolescence. Neuroscience 166, 168-177. doi: 10.1016/j.neuroscience.2009.12.016

Pittman, Q. J., Blume, H. W., and Renaud, L. P. (1981). Connections of the hypothalamic paraventricular nucleus with the neurohypophysis, median eminence, amygdala, lateral septum and midbrain periaqueductal gray: an electrophysiological study in the rat. Brain Res. 215, 15-28. doi: 10.1016/00068993(81)90488-1

Pitts, A. F., Samuelson, S. D., Meller, W. H., Bissette, G., Nemeroff, C. B., and Kathol, R. G. (1995). Cerebrospinal fluid corticotropin-releasing hormone, vasopressin, and oxytocin concentrations in treated patients with major depression and controls. Biol. Psychiatry 38, 330-335. doi: 10.1016/00063223(95)00229-A

Purba, J. S., Hoogendijk, W. J., Hofman, M. A., and Swaab, D. F. (1996). Increased number of vasopressin-and oxytocin-expressing neurons in the paraventricular nucleus of the hypothalamus in depression. Arch. Gen. Psychiatry 53, 137-143. doi: 10.1001/archpsyc.1996.01830020055007

Qin, J., Feng, M., Wang, C., Ye, Y., Wang, P. S., and Liu, C. (2009). Oxytocin receptor expressed on the smooth muscle mediates the excitatory effect of oxytocin on gastric motility in rats. Neurogastroenterol. Motil. 21, 430-438. doi: 10.1111/j.1365-2982.2009.01282.x

Rapoport, J. L., and Wise, S. P. (1988). Obsessive-compulsive disorder: evidence for basal ganglia dysfunction. Psychopharmacol. Bull. 24, 380-384.

Rault, J. L., Carter, C. S., Garner, J. P., Marchant-Forde, J. N., Richert, B. T., Lay, D. C., et al. (2013). Repeated intranasal oxytocin administration in early life dysregulates the HPA axis and alters social behavior. Physiol. Behav. 112-113, 40-48. doi: 10.1016/j.physbeh.2013.02.007

Reeta, K. h., Mediratta, P. K., Rathi, N., Jain, H., Chugh, C., and Sharma, K. K. (2006). Role of kappa- and delta-opioid receptors in the antinociceptive effect of oxytocin in formalin-induced pain response in mice. Regul. Pept. 135, 85-90. doi: 10.1016/j.regpep.2006.04.004

Renaud, L. P., Tang, M., McCann, M. J., Stricker, E. M., and Verbalis, J. G. (1987). Cholecystokinin and gastric distension activate oxytocinergic cells in rat hypothalamus. Am. J. Physiol. 253, R661-R665.

Rhodes, C. H., Morrell, J. I., and Pfaff, D. W. (1981). Immunohistochemical analysis of magnocellular elements in rat hypothalamus: distribution and numbers of cells containing neurophysin, oxytocin, and vasopressin. J. Comp. Neurol. 198, 45-64. doi: 10.1002/cne.901980106

Richard, P., Moos, F., Dayanithi, G., Gouzènes, L., and Sabatier, N. (1997). Rhythmic activities of hypothalamic magnocellular neurons: autocontrol mechanisms. Biol. Cell. 89, 555-560. doi: 10.1111/j.1768-322X.1997.tb01032.x
Rinaman, L. (1998). Oxytocinergic inputs to the nucleus of the solitary tract and dorsal motor nucleus of the vagus in neonatal rats. J. Comp. Neurol. 399, 101-109.

Robbe, D., Kopf, M., Remaury, A., Bockaert, J., and Manzoni, O. J. (2002). Endogenous cannabinoids mediate long-term synaptic depression in the nucleus accumbens. Proc. Natl. Acad. Sci. U.S.A. 99, 8384-8388. doi: 10.1073/pnas.122149199

Robinson, G., and Evans, J. J. (1990). Oxytocin has a role in gonadotrophin regulation in rats. J. Endocrinol. 125, 425-432. doi: 10.1677/joe.0.1250425

Rogers, R. C., and Hermann, G. E. (1987). Oxytocin, oxytocin antagonist, TRH, and hypothalamic paraventricular nucleus stimulation effects on gastric motility. Peptides 8, 505-513. doi: 10.1016/0196-9781(87)90017-9

Ross, H. E., and Young, L. J. (2009). Oxytocin and the neural mechanisms regulating social cognition and affiliative behavior. Front. Neuroendocrinol. 30, 534-547. doi: 10.1016/j.yfrne.2009.05.004

Rubenstein, J. L., and Merzenich, M. M. (2003). Model of autism: increased ratio of excitation/inhibition in key neural systems. Genes Brain Behav. 5, 255-267. doi: 10.1034/j.1601-183X.2003.00037.x

Russell, J. A., Leng, G., and Douglas, A. J. (2003). The magnocellular oxytocin system, the fount of maternity: adaptations in pregnancy. Front. Neuroendocrinol. 24, 27-61. doi: 10.1016/S0091-3022(02)00104-8

Ryan, B. C., Young, N. B., Crawley, J. N., Bodfish, J. W., and Moy, S. S. (2009). Social deficits, stereotypy and early emergence of repetitive behavior in the C58/J inbred mouse strain. Behav. Brain Res. 208, 178-188. doi: 10.1016/j.bbr.2009.11.031

Salonia, A., Nappi, R. E., Pontillo, M., Daverio, R., Smeraldi, A., Briganti, A., et al. (2005). Menstrual cycle-related changes in plasma oxytocin are relevant to normal sexual function in healthy women. Horm. Behav. 47, 164-169. doi: 10.1016/j.yhbeh.2004.10.002

Sanders, G., Freilicher, J., and Lightman, S. L. (1990). Psychological stress of exposure to uncontrollable noise increases plasma oxytocin in high emotionality women. Psychoneuroendocrinology 15, 47-58. doi: 10.1016/03064530(90)90046-C

Sarnyai, Z., Bíró, E., Babarczy, E., Vecsernyés, M., Laczi, F., Szabó, G., et al. (1992a). Oxytocin modulates behavioural adaptation to repeated treatment with cocaine in rats. Neuropharmacology 31, 593-598. doi: 10.1016/0028-3908(92)90192-R

Sarnyai, Z., and Kovács, G. L. (1994). Role of oxytocin in the neuroadaptation to drugs of abuse. Psychoneuroendocrinology 19, 85-117. doi: 10.1016/03064530(94)90062-0

Sarnyai, Z., Szabó, G., Kovács, G. L., and Telegdy, G. (1992b). Opposite actions of oxytocin and vasopressin in the development of cocaine-induced behavioral sensitization in mice. Pharmacol. Biochem. Behav. 43, 491-494. doi: 10.1016/0091-3057(92)90182-F

Sasayama, D., Hattori, K., Teraishi, T., Hori, H., Ota, M., Yoshida, S., et al. (2012). Negative correlation between cerebrospinal fluid oxytocin levels and negative symptoms of male patients with schizophrenia. Schizophr. Res. 139, 201-206. doi: 10.1016/j.schres.2012.06.016

Scantamburlo, G., Ansseau, M., Geenen, V., and Legros, J. J. (2011). Intranasal oxytocin as an adjunct to escitalopram in major depression. J. Neuropsychiatry Clin. Neurosci. 23:E5. doi: 10.1176/jnp.23.2.jnpe5

Scantamburlo, G., Hansenne, M., Fuchs, S., Pitchot, W., Maréchal, P., Pequeux, C., et al. (2007). Plasma oxytocin levels and anxiety in patients with major depression. Psychoneuroendocrinology 32, 407-410. doi: 10.1016/j.psyneuen.2007.01.009

Scantamburlo, G., Hansenne, M., Fuchs, S., Pitchot, W., Pinto, E., Reggers, J., et al. (2005). AVP- and OT-neurophysins response to apomorphine and clonidine in major depression. Psychoneuroendocrinology 30, 839-845. doi: 10.1016/j.psyneuen.2005.04.015

Schaller, F., Watrin, F., Sturny, R., Massacrier, A., Szepetowski, P., and Muscatelli, F. (2010). A single postnatal injection of oxytocin rescues the lethal feeding behaviour in mouse newborns deficient for the imprinted Magel2 gene. Hum. Mol. Genet. 19, 4895-4905. doi: 10.1093/hmg/ddq424

Scott, A. I., Shering, P. A., Legros, J. J., and Whalley, L. J. (1991). Improvement in depressive illness is not associated with altered release of neurophysins over a course of ECT. Psychiatry Res. 36, 65-73. doi: 10.1016/0165-1781(91)90118-9

Scott, A. I., Whalley, L. J., Bennie, J., and Bowler, G. (1986). Oestrogenstimulated neurophysin and outcome after electroconvulsive therapy. Lancet 1, 1411-1414. doi: 10.1016/S0140-6736(86)91557-6 
Scott, A. I., Whalley, L. J., and Legros, J. J. (1989). Treatment outcome, seizure duration, and the neurophysin response to ECT. Biol. Psychiatry 25, 585-597. doi: 10.1016/0006-3223(89)90219-9

Shahrokh, D. K., Zhang, T. Y., Diorio, J., Gratton, A., and Meaney, M. J. (2010). Oxytocin-dopamine interactions mediate variations in maternal behavior in the rat. Endocrinology 151, 2276-2286. doi: 10.1210/en.2009-1271

Shin, N. Y., Park, H. Y., Jung, W. H., Park, J. W., Yun, J. Y., Jang, J. H., et al. (2015). Effects of oxytocin on neural response to facial expressions in patients with Schizophrenia. Neuropsychopharmacology 40, 1919-1927. doi: 10.1038/npp.2015.78

Sichel, D. A., Cohen, L. S., Dimmock, J. A., and Rosenbaum, J. F. (1993). Postpartum obsessive compulsive disorder: a case series. J. Clin. Psychiatry 54, 156-159.

Smith, J. E., Williams, K., Burkett, S., Glue, P., and Nutt, D. J. (1990). Oxytocin and vasopressin responses to ECT. Psychiatry Res. 32, 201-202. doi: 10.1016/01651781(90)90087-L

Smith, J., Williams, K., Birkett, S., Nicholson, H., Glue, P., and Nutt, D. J. (1994). Neuroendocrine and clinical effects of electroconvulsive therapy and their relationship to treatment outcome. Psychol. Med. 24, 547-555. doi: 10.1017/S0033291700027707

South, M., Larson, M. J., White, S. E., Dana, J., and Crowley, M. J. (2011). Better fear conditioning is associated with reduced symptom severity in autism spectrum disorders. Autism Res. 4, 412-421. doi: 10.1002/aur.221

Souza, R. P., de Luca, V., Meltzer, H. Y., Lieberman, J. A., and Kennedy, J. L. (2010). Schizophrenia severity and clozapine treatment outcome association with oxytocinergic genes. Int. J. Neuropsychopharmacol. 13, 793-798. doi: 10.1017/S1461145710000167

Strauss, G. P., Keller, W. R., Koenig, J. I., Gold, J. M., Frost, K. H., and Buchanan, R. W. (2015). Plasma oxytocin levels predict social cue recognition in individuals with schizophrenia. Schizophr. Res. 162, 47-51. doi: 10.1016/j.schres.2015.01.034

Swaab, D. F., Pool, C. W., and Nijveldt, F. (1975). Immunofluorescence of vasopressin and oxytocin in the rat hypothalamo-neurohypophypopseal system. J. Neural Transm. 36, 195-215. doi: 10.1007/BF012 53126

Swaab, D. F., Purba, J. S., and Hofman, M. A. (1995). Alterations in the hypothalamic paraventricular nucleus and its oxytocin neurons (putative satiety cells) in Prader-Willi syndrome: a study of five cases. J. Clin. Endocrinol. Metab. 80, 573-579.

Swanson, L. W., and Kuypers, H. G. (1980). The paraventricular nucleus of the hypothalamus: cytoarchitectonic subdivisions and organization of projections to the pituitary, dorsal vagal complex, and spinal cord as demonstrated by retrograde fluorescence double-labeling methods. J. Comp. Neurol. 194, 555-570. doi: 10.1002/cne.901940306

Swarbrick, M. M., Evans, D. S., Valle, M. I., Favre, H., Wu, S. H., Njajou, O. T., et al. (2011). Replication and extension of association between common genetic variants in SIM1 and human adiposity. Obesity (Silver Spring) 19, 2394-2403. doi: 10.1038/oby.2011.79

Szabó, G., Kovács, G. L., and Telegdy, G. (1989). Intraventricular administration of neurohypophyseal hormones interferes with the development of tolerance to ethanol. Acta Physiol. Hung. 73, 97-103.

Tachibana, M., Kagitani-Shimono, K., Mohri, I., Yamamoto, T., Sanefuji, W., Nakamura, A., et al. (2013). Long-term administration of intranasal oxytocin is a safe and promising therapy for early adolescent boys with autism spectrum disorders. J. Child Adolesc. Psychopharmacol. 23, 123-127. doi: 10.1089/cap.2012.0048

Takayanagi, Y., Kasahara, Y., Onaka, T., Takahashi, N., Kawada, T., and Nishimori, K. (2008). Oxytocin receptor-deficient mice developed late-onset obesity. Neuroreport 19, 951-955. doi: 10.1097/WNR.0b013e3283021ca9

Takayanagi, Y., Yoshida, M., Bielsky, I. F., Ross, H. E., Kawamata, M., Onaka, T., et al. (2005). Pervasive social deficits, but normal parturition, in oxytocin receptor-deficient mice. Proc. Natl. Acad. Sci. U.S.A. 102, 16096-16101. doi: 10.1073/pnas.0505312102

Tang, M., Zhang, J., Xu, L., and Chen, J. D. (2006). Implantable gastric stimulation alters expression of oxytocin- and orexin-containing neurons in the hypothalamus of rats. Obes. Surg. 16, 762-769. doi: $10.1381 / 096089206777346745$
Tansey, K. E., Brookes, K. J., Hill, M. J., Cochrane, L. E., Gill, M., Skuse, D., et al. (2010). Oxytocin receptor (OXTR) does not play a major role in the aetiology of autism: Genetic and molecular studies. Neurosci. Lett. 474, 163-167. doi: 10.1016/j.neulet.2010.03.035

Tauber, M., Mantoulan, C., Copet, P., Jauregui, J., Demeer, G., Diene, G., et al. (2011). Oxytocin may be useful to increase trust in others and decrease disruptive behaviours in patients with Prader-Willi syndrome: a randomised placebo-controlled trial in 24 patients. Orphanet J. Rare Dis. 6:47. doi: 10.1186/1750-1172-6-47

Teltsh, O., Kanyas-Sarner, K., Rigbi, A., Greenbaum, L., Lerer, B., and Kohn, Y. (2012). Oxytocin and vasopressin genes are significantly associated with schizophrenia in a large Arab-Israeli pedigree. Int. J. Neuropsychopharmacol. 15, 309-319. doi: 10.1017/S1461145711001374

Teng, B. L., Nonneman, R. J., Agster, K. L., Nikolova, V. D., Davis, T. T., Riddick, N. V., et al. (2013). Prosocial effects of oxytocin in two mouse models of autism spectrum disorders. Neuropharmacology 72, 187-196. doi: 10.1016/j.neuropharm.2013.04.038

Thompson, M. R., Callaghan, P. D., Hunt, G. E., Cornish, J. L., and McGregor, I. S. (2007). A role for oxytocin and 5-HT(1A) receptors in the prosocial effects of 3,4 methylenedioxymethamphetamine ("ecstasy"). Neuroscience 146, 509-514. doi: 10.1016/j.neuroscience.2007.02.032

Tóth, Z. E., Gallatz, K., Fodor, M., and Palkovits, M. (1999). Decussations of the descending paraventricular pathways to the brainstem and spinal cord autonomic centers. J. Comp. Neurol. 414, 255-266.

Tyzio, R., Cossart, R., Khalilov, I., Minlebaev, M., Hübner, C. A., Represa, A., et al. (2006). Maternal oxytocin triggers a transient inhibitory switch in GABA signaling in the fetal brain during delivery. Science 314, 1788-1792. doi: $10.1126 /$ science. 1133212

Tyzio, R., Nardou, R., Ferrari, D. C., Tsintsadze, T., Shahrokhi, A., Eftekhari, S., et al. (2014). Oxytocin-mediated GABA inhibition during delivery attenuates autism pathogenesis in rodent offspring. Science 343, 675-679. doi: $10.1126 /$ science. 1247190

Ueta, Y., Kannan, H., Higuchi, T., Negoro, H., Yamaguchi, K., and Yamashita, H. (2000). Activation of gastric afferents increases noradrenaline release in the paraventricular nucleus and plasma oxytocin level. J. Auton. Nerv. Syst. 78, 69-76. doi: 10.1016/S0165-1838(99)00049-1

Uvnäs-Moberg, K., Bruzelius, G., Alster, P., and Lundeberg, T. (1993). The antinociceptive effect of non-noxious sensory stimulation is mediated partly through oxytocinergic mechanisms. Acta Physiol. Scand. 149, 199-204. doi: 10.1111/j.1748-1716.1993.tb09612.x

Van Erp, A. M., Kruk, M. R., Semple, D. M., and Verbeet, D. W. (1993). Initiation of self-grooming in resting rats by local $\mathrm{PVH}$ infusion of oxytocin but not a -MSH. Brain Res. 607, 108-112. doi: 10.1016/0006-8993(93)91494-D

van Londen, L., Goekoop, J. G., van Kempen, G. M., Frankhuijzen-Sierevogel, A. C., Wiegant, V. M., van der Velde, E. A., et al. (1997). Plasma levels of arginine vasopressin elevated in patients with major depression. Neuropsychopharmacology 17, 284-292. doi: 10.1016/S0893-133X(97)00054-7

Vannucchi, G., Masi, G., Toni, C., Dell'Osso, L., Marazziti, D., and Perugi, G. (2014). Clinical features, developmental course, and psychiatric comorbidity of adult autism spectrum disorders. CNS Spectr. 19, 157-164. doi: 10.1017/S1092852913000941

van Tol, H. H., van den Buuse, M., de Jong, W., and Burbach, J. P. (1988). Vasopressin and oxytocin gene expression in the supraoptic and paraventricular nucleus of the spontaneously hypertensive rat (SHR) during development of hypertension. Brain Res. 464, 303-311. doi: 10.1016/0169-328X(88)90039-3

Viero, C., Shibuya, I., Kitamura, N., Verkhratsky, A., Fujihara, H., Katoh, A., et al. (2010). Oxytocin: crossing the bridge between basic science and pharmacotherapy. CNS Neurosci. Ther. 16, e138-e156. doi: 10.1111/j.17555949.2010.00185.x

Viviani, D., Charlet, A., van den Burg, E., Robinet, C., Hurni, N., Abatis, M., et al. (2011). Oxytocin selectively gates fear responses through distinct outputs from the central amygdala. Science 333, 104-107. doi: 10.1126/science.1201043

von Eggelkraut-Gottanka, R., and Beck-Sickinger, A. G. (2004). Biosynthesis of peptide hormones derived from precursor sequences. Curr. Med. Chem. 11, 2651-2665. doi: 10.2174/0929867043364405

Wei, D., Lee, D., Cox, C. D., Karsten, C. A., Peñagarikano, O., Geschwind, D. H., et al. (2015). Endocannabinoid signaling mediates oxytocin-driven 
social reward. Proc. Natl. Acad. Sci. U.S.A. 112, 14084-14089. doi: 10.1073/pnas.1509795112

Whalley, L. J., Eagles, J. M., Bowler, G. M., Bennie, J. G., Dick, H. R., McGuire, R. J., et al. (1987). Selective effects of ECT on hypothalamic-pituitary activity. Psychol. Med. 17, 319-328. doi: 10.1017/S0033291700024855

Whalley, L. J., Rosie, R., Dick, H., Levy, G., Watts, A. G., Sheward, W. J., et al. (1982). Immediate increases in plasma prolactin and neurophysin but not other hormones after electroconvulsive therapy. Lancet 2, 1064-1068. doi: 10.1016/S0140-6736(82)90004-6

Wharton, R. H., and Bresnan, M. J. (1989). Neonatal respiratory depression and delay in diagnosis in Prader-Willi syndrome. Dev. Med. Child Neurol. 31, 231-236. doi: 10.1111/j.1469-8749.1989.tb03983.x

Williams, J. R., Insel, T. R., Harbaugh, C. R., and Carter, C. S. (1994). Oxytocin administered centrally facilitates formation of a partner preference in female prairie voles (Microtus ochrogaster). J. Neuroendocrinol. 6, 247-250. doi: 10.1111/j.1365-2826.1994.tb00579.x

Williams, P. D., Bock, M. G., Evans, B. E., Freidinger, R. M., and Pettibone, D. J. (1998). Progress in the development of oxytocin antagonists for use in preterm labor. Adv. Exp. Med. Biol. 449, 473-479. doi: 10.1007/978-1-4615-4871-3_61

Witt, D. M., Carter, C. S., and Walton, D. M. (1990). Central and peripheral effects of oxytocin administration in prairie voles (Microtus ochrogaster). Pharmacol. Biochem. Behav. 37, 63-69. doi: 10.1016/0091-3057(90) 90042-G

Wolff, K., Tsapakis, E. M., Winstock, A. R., Hartley, D., Holt, D., Forsling, M. L., et al. (2006). Vasopressin and oxytocin secretion in response to the consumption of ecstasy in a clubbing population. J. Psychopharmacol. 20, 400-410. doi: 10.1177/0269881106061514

Wu, C. L., Doong, M. L., and Wang, P. S. (2008). Involvement of cholecystokinin receptor in the inhibition of gastrointestinal motility by oxytocin in ovariectomized rats. Eur. J. Pharmacol. 580, 407-415. doi: 10.1016/j.ejphar.2007.11.024

Wu, C. L., Hung, C. R., Chang, F. Y., Pau, K. Y., and Wang, P. S. (2003). Pharmacological effects of oxytocin on gastric emptying and intestinal transit of a non-nutritive liquid meal in female rats. Naunyn Schmiedebergs. Arch. Pharmacol. 367, 406-413. doi: 10.1007/s00210-003-0690-y

Wu, S., Jia, M., Ruan, Y., Liu, J., Guo, Y., Shuang, M., et al. (2005). Positive association of the oxytocin receptor gene (OXTR) with autism in the Chinese Han population. Biol. Psychiatry 58, 74-77. doi: 10.1016/j.biopsych. 2005.03.013

Xi, D., Gandhi, N., Lai, M., and Kublaoui, B. M. (2012). Ablation of Sim1 neurons causes obesity through hyperphagia and reduced energy expenditure. PLoS ONE 7:e36453. doi: 10.1371/journal.pone. 0036453

Xu, X. J., and Wiesenfeld-Hallin, Z. (1994). Intrathecal oxytocin facilitates the spinal nociceptive flexor reflex in the rat. Neuroreport 5, 750-752. doi: 10.1097/00001756-199403000-00003
Yang, J. (1976). Intrathecal administration of oxytocin induces analgesia in low back pain involving the endogenous opiate peptide system. Spine (Phila $\mathrm{Pa}$ 1976) 19, 867-871. doi: 10.1097/00007632-199404150-00001

Yang, J., Yang, Y., Chen, J. M., Liu, W. Y., Wang, C. H., and Lin, B. C. (2007b). Effect of oxytocin on acupuncture analgesia in the rat. Neuropeptides 41, 285-292. doi: 10.1016/j.npep.2007.05.004

Yang, J., Yang, Y., Chen, J. M., Liu, W. Y., Wang, C. H., and Lin, B. C. (2007a). Central oxytocin enhances antinociception in the rat. Peptides 28, 1113-1119. doi: 10.1016/j.peptides.2007.03.003

Young, K. A., Gobrogge, K. L., Liu, Y., and Wang, Z. (2011). The neurobiology of pair bonding: insights from a socially monogamous rodent. Front. Neuroendocrinol. 32, 53-69. doi: 10.1016/j.yfrne.2010. 07.006

Young, K. A., Liu, Y., and Wang, Z. (2008). The neurobiology of social attachment: A comparative approach to behavioral, neuroanatomical, and neurochemical studies. Comp. Biochem. Physiol. C. Toxicol. Pharmacol. 148, 401-410. doi: 10.1016/j.cbpc.2008.02.004

Yrigollen, C. M., Han, S. S., Kochetkova, A., Babitz, T., Chang, J. T., Volkmar, F. R., et al. (2008). Genes controlling affiliative behavior as candidate genes for autism. Biol. Psychiatry 63, 911-916. doi: 10.1016/j.biopsych.2007.11.015

Zaninetti, M., and Raggenbass, M. (2000). Oxytocin receptor agonists enhance inhibitory synaptic transmission in the rat hippocampus by activating interneurons in stratum pyramidale. Eur. J. Neurosci. 12, 3975-3984. doi: 10.1046/j.1460-9568.2000.00290.x

Zhang, G., Bai, H., Zhang, H., Dean, C., Wu, Q., Li, J., et al. (2011). Neuropeptide exocytosis involving synaptotagmin-4 and oxytocin in hypothalamic programming of body weight and energy balance. Neuron 69, 523-535. doi: 10.1016/j.neuron.2010.12.036

Zhang, G., and Cai, D. (2011). Circadian intervention of obesity development via resting-stage feeding manipulation or oxytocin treatment. Am. J. Physiol. Endocrinol. Metab. 301, E1004-E1012. doi: 10.1152/ajpendo.00196.2011

Zimmerman, E. A., Nilaver, G., Hou-Yu, A., and Silverman, A. J. (1984). Vasopressinergic and oxytocinergic pathways in the central nervous system. Fed. Proc. 43, 91-96.

Conflict of Interest Statement: The authors declare that the research was conducted in the absence of any commercial or financial relationships that could be construed as a potential conflict of interest.

Copyright (c) 2016 Romano, Tempesta, Micioni Di Bonaventura and Gaetani. This is an open-access article distributed under the terms of the Creative Commons Attribution License (CC BY). The use, distribution or reproduction in other forums is permitted, provided the original author(s) or licensor are credited and that the original publication in this journal is cited, in accordance with accepted academic practice. No use, distribution or reproduction is permitted which does not comply with these terms. 